AL-QANȚARA (AQ)

XXVII 2, julio-diciembre de 2006

pp. $337-374$

ISSN 0211-3589

\title{
VIEJAS Y NUEVAS MONEDAS EN LA CIUDAD EMIRAL DE MADINATT IYYUH (EL TOLMO DE MINATEDA, HELLÍN, ALBACETE) ${ }^{1}$
}

\author{
CAROLINA DOMÉNECH Belda \\ SONIA GUTIÉRREZ LLORET \\ Universidad de Alicante
}

Las viejas monedas de oro y de plata del país eran de origen antiguo y desconocido en su mayor parte, aunque algunas eran romanas; eran monedas muy mal conformadas, (...), y era tal su desgaste con el uso, que los dibujos que tenian resultaban tan imposibles de leer como si fuesen ampollas y lo parecían.

(Mark Twain, Un yanqui en la Corte del rey Arturo)

Los trabajos arqueológicos llevados a cabo en El Tolmo de Minateda (Hellín, Albacete) han permitido sacar a la luz los vestigios de una ciudad visigoda y posteriormente islámica que fue abandonada durante la segunda mitad del siglo IX. En los contextos de uso, abandono y destrucción de la ciudad emiral se han exhumado una serie de monedas, tanto islámicas como acuñadas en períodos anteriores. La contextualización del registro numismático permite obtener una visión de conjunto de la circulación monetaria en esta ciudad emiral y plantear algunas implicaciones de carácter histórico, numismático y arqueológico.

Palabras clave: Numismática; arqueología; emirato; al-Andalus.
The archaeological fieldwork carried out in El Tolmo de Minateda (Hellín, Albacete) has made it possible to recover the traces of an Islamic and Visigoth town that was abandoned during the second half of the $9^{\text {th }}$ century AC. In the archaeological contexts of use, abandonment and destruction of the emiral town, a series of coins both Islamic and of earlier periods have been found. The contextualization of the numismatic record permits a comprehensive vision of the monetary circulation in this emiral town and allows us to offer some further views of historical, numismatic and archaeological character.

Keywords: Numismatics; Archaeology; Emirate; al-Andalus.

${ }^{1}$ Los repertorios numismáticos estudiados en este trabajo han sido exhumados en el marco del proyecto sistemático "Tolmo de Minateda", financiado por la Consejería de Educación y Cultura de la Junta de Comunidades de Castilla, y están depositados en el Museo de Albacete, a cuya dirección agradecemos las facilidades dadas en la consulta de sus fondos. Este trabajo no podría haberse realizado sin la colaboración desinteresada de José Antonio Mellado Ribera, Juan Manuel Abascal Palazón y Antonio Alberola Belda en la catalogación del repertorio numismático romano; Víctor Cañavate Castejón en la contextualización estratigráfica de los hallazgos, y Julia Sarabia Bautista en la representación gráfica. 


\section{La ciudad y su historia}

El Tolmo de Minateda es un cerro amesetado de unas diez hectáreas de extensión situado en la pedanía de Minateda, cerca de Hellín en la actual provincia de Albacete (fig. 1a); desde su estratégica posición en el valle del arroyo de Tobarra, afluente del río Mundo, domina el camino natural que comunica la Meseta con la costa mediterránea - antiguo trazado de la vía de Carthago Noua a Complutum en época romana y a Toledo en la Edad Media - de un lado, y la alta Andalucía con Valencia, de otro. Esta privilegiada situación explica la dilatada ocupación del cerro, habitado con continuidad desde la Prehistoria hasta el Medievo, y su mantenimiento posterior como núcleo viario.

Una afortunada concurrencia de testimonios escritos y materiales, discutida por extenso en otros foros ${ }^{2}$, ha permitido reconocer históricamente el yacimiento, hasta el punto de que en el estado actual de las investigaciones parece probada su identificación con una de las ciudades mencionadas en el Pacto de Teodomiro del año 713, Madinat Iyyuh ${ }^{3}$, probable trasunto en época islámica de la sede episcopal Eiotana o Elotana, creada junto con Begastri a finales del siglo VI o principios del VII para integrar los territorios dependientes de los obispados de Ilici y Carthago Noua, todavía en manos imperiales ${ }^{4}$; dicha

\footnotetext{
2 Gutiérrez Lloret, S., "La identificación de Madīnat Iyyuh y su relación con la sede episcopal Elotana. Nuevas perspectivas sobre viejos problemas", Scripta in Honorem E.A. Llobregat, Alicante, 2000, 481-501, y la reciente revisión, de Gutiérrez Lloret, S., Abad Casal, L., y Gamo Parras, B., "Eio, Iyyuh y el Tolmo de Minateda (Hellín, Albacete): de sede episcopal a madîna islámica", VI Reunión de Arqueología Cristiana Hispáni$c a$ (València, 2003), en prensa, de donde proceden algunos de los argumentos que se resumen a continuación.

${ }^{3}$ Con discrepancias en la transcripción de su nombre según autores: "Iyih" en al-'Uḍī, "Ānah" en Ibn Ḥayyān e "Il.h" en Ibn 'Iḍārī y al-Himyarī (cfr. Ibn Ḥayyān, Crónica de los emires Alhakam y 'Abdarrahmmān II entre los años 796 y 847, Makkī, M. 'A. y Corriente, F. (trads.), Zaragoza, 2001, 284, n. 590). En un principio, el equipo científico del Proyecto Tolmo se había inclinado por la versión del autor más antiguo, al-'Udrī, que vocalizaba el topónimo con kasra. Sin embargo, la autorizada opinión de Federico Corriente nos ha llevado a reconsiderar esa transcripción, teniendo en cuenta que en la reciente traducción del Almuqtabis II-1, M. 'A. Makkī y el propio F. Corriente han preferido la transcripción Iyyuh, acorde con la clásica del propio traductor de al-'Udrī: "La cora de Tudmīr según al-'Uḍī (s. XI). Aportaciones al estudio geográfico-descriptivo del SE peninsular", Cuadernos de Historia del Islam 4, Serie monográfica, n. ${ }^{\circ}$ 3, 1972.

4 Vives, J., "Nuevas diócesis visigodas ante la invasión bizantina", Spanische Forschungen, 17 (1961), 1-9.
}

Al-Qanțara (AQ) XXVII 2, julio-diciembre 2006, pp. 337-374 ISSN 0211-3589 
FIguRA1a.-Localización geográfica del Tolmo de Minateda; b: Ubicación del barrio emiral
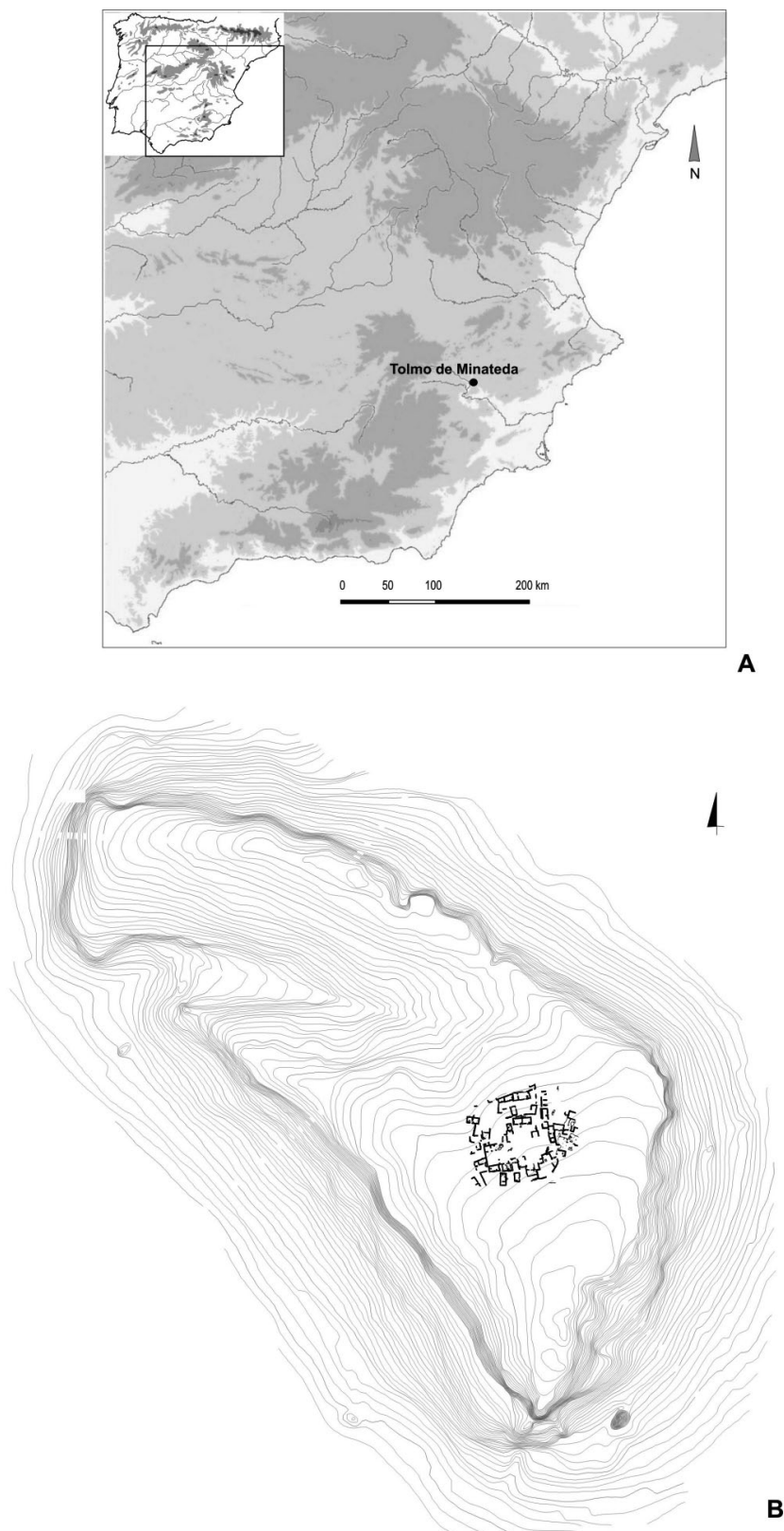

Al-Qantara (AQ) XXVII 2, julio-diciembre 2006, pp. 337-374 ISSN 0211-3589 
identificación se apoya en una evolución fonética bien atestiguada toponímica y documentalmente -Madinat Iyyuh $>$ Madinat Iyyah $>$ Medina Tea $>$ Minateda—, a más de las referencias geográficas implícitas en las fuentes que la mencionan ${ }^{5}$.

Como madina aparece citada en las versiones del Pacto de Teodomiro transmitidas por al-'Uḍrī, al-Rušātī según compendio de Ibn al-Jarrāt, al-Ḍabbī y quizás en la de al-Ḥimyarī, mientras que el geógrafo al-Zuhrī se refiere a ella en este mismo sentido al describir el curso del río Segura ${ }^{6}$. El geógrafo al-'Uḍī también menciona una ciudad de Iyih en la vía de Cartagena a Toledo, entre Cieza y Tobarra, y un distrito (iqlim) agrícola con el epíteto de «al-sahl», es decir Iyih «del Llano» en la Cora de Tudmī ${ }^{7}$. Por último, la destrucción de una ciudad de ese nombre se menciona en diversas fuentes árabes (al-'Udrī, Ibn 'Iḍārī, al-Himyarī e Ibn Hayyān) en relación al célebre episodio de la fundación de Murcia por parte del emir 'Abd al-Raḥmān II como nueva capital del territorio de Tudmīr alrededor del año $825^{8}$.

5 Gutiérrez Lloret, S., Abad Casal, L. y Gamo Parras, B., "Eio, Iyyuh y El Tolmo de Minateda (Hellín, Albacete) de sede episcopal a Madina islámica", VI Reunió d'Arqueologia Cristiana Hispànica (Valencia, 2003), Barcelona, 2005, 345-370.

6 Al-'Uḍī, al-Masālik ilà ŷamī' al-mamālik, ed. 'A. 'A. al-Ahwānī, Madrid, 1965, 5; Molina López, E., "La cora de Tudmīr”, 58-59; Ibn al-Jarrāṭ (al-Rušātī e Ibn al-Jarrāt, Al-Andalus en el Kitāb Iqtibās al-anwār y el Ijtișār Iqtibās al-anwār, Molina López, E. y Bosch Vilá, J. (eds.), Madrid, 1990, 33); al-Dabbì (ms. 1676, fol. 84v, Biblioteca del Escorial) Molina López, E. y Pezzi de Vidal, E., "Últimas aportaciones al estudio de la cora de Tudmī (Murcia). Precisiones y rectificaciones", Cuadernos de Historia del Islam, 7 (1975-76), 83-111); al-Himyarī, Kitāb al-Rawd al-mi' 'tār fì jabar al-aqțār, ed. I. 'Abbās, Beirut, 1980, 132, y Lévi Provençal, É., La Péninsule Ibérique au Moyen Âge d'après le Kitāb Raw ̣̣ al-mi 'țār fi habar al-aqțār, Leiden, 1938, 62-3; al-Zuhrī, Kitāb al-Dja 'rāfiyya. Mappemonde du Califa al-Ma'mūn reprodouite par Fazari (IIIe/IXe ss) reéditée et commentée par al-Zuhrī, ed. M. Hadj-Sadok, Damasco, 1968, 207. Una recopilación de las diversas menciones, en Molina López, E. y Pezzi de Vidal, E., "Últimas aportaciones", y en Pocklington, R., "El emplazamiento de Iyi(h)", Sharq al-Andalus, 4 (1987), 4-44.

7 Al-'Udrī, al-Masālik, 3-4; Molina López, E., "La cora de Tudmīr”, 51 y ss.

8 A las noticias clásicas de al-'Uḍī, al-Masālik, 6 (y Molina López, E., "La cora de Tudmīr", 62 y ss.), Ibn 'Id̄ārī [Dozy, R., Histoire de l'Afrique et de l'Espagne intitulée al-Bayano' l-mogrib par Ibn Adhari (de Maroc) et fragments de la chronique de Arib (de Cordoue), Leiden, 1848-51, 84-5] y al-Himyarī (Lévi-Provençal, É., La Péninsule Ibérique, 181 y 218), se añade recientemente la de Ibn Hayyān del segundo volumen de al-Muqtabis, cuyo manuscrito original localizado por E. Lévi-Provençal en los años treinta ha sido objeto de una edición facsímil (Kitāb al-Muqtabis fì ta'rỉj riŷāl al-Andalus, Vallvé, J. (ed.), Madrid, 1999) y una traducción a cuyas páginas remitimos: Crónica de los emires Alhakam I y 'Abdarrahnnān II entre los años 796 y 847 (Almuqtabis III), Makki, M.A. y Corriente, F. (trads.), Zaragoza, 2001, 284). Todos los textos pueden verse en Pocklington, R., "El emplazamiento de Iyi(h)", Sharq al-Andalus, 4 (1987), 
Por otro lado, la sede episcopal Eiotana o Elotana aparece por vez primera en la Constitutio Carthaginensium sacerdotum - un concilio provincial de la Cartaginense celebrado en Toledo el 23 de octubre de 610 - que supuestamente refrenda el Decretum de Gundemaro dado en confirmación de los derechos metropolitanos de la sede toledana sobre la provincia cartaginense; este controvertido Sínodo de Gundemaro contiene la mención del primer obispo de dicha sede, Sanabilis «sanctae ecclesiae Elotanae episcopus» ${ }^{9}$, que a lo largo del siglo VII vuelve a mencionarse con ocasión de al menos dos concilios, el VII Concilio de Toledo (646) y el XI de la misma ciudad (675), a los que quizá se pueda añadir el XV (688); en todos ellos figura ya siempre asociada al obispado de Ilici — con los obispos Vinibal, Leander y posiblemente Emmila - , que debió de absorber la sede Elotana ${ }^{10}$.

De hecho, el proyecto arqueológico sistemático que viene desarrollándose con continuidad desde 1988 ha permitido documentar los restos de una importante ciuitas visigoda erigida prácticamente ex nouo a finales del siglo VI o principios del VII, sobre las ruinas de un municipio romano prácticamente abandonado en época altoimperial. Esta intensa ocupación urbana de época visigoda, con continuidad estratigráfica en el Emirato, responde a un programa integral que comprende diversas actuaciones entre las que destaca, por su gran significado edilicio, la erección de un complejo monumental de carácter religioso en la parte alta de la ciudad, compuesto por la basílica de tres naves con su baptisterio ${ }^{11}$, el cementerio ad sanctos y un edificio frontero que probablemente corresponda al palatium, además de la fortificación del principal acceso a la ciudad y la ocupación urbana de toda la superficie del cerro.

175-198, y en Carmona González, A., "Murcia ¿una fundación árabe? (nuevos datos y conclusiones)", Murcia musulmana, Murcia, 1989, 85-147. Una discusión sobre el problema, en Gutiérrez Lloret, S., La cora de Tudmìr. De la antigüedad tardia al mundo islámico, Madrid-Alicante, 1996, 271-4.

9 Concilios visigóticos e hispano-romanos, Vives, J. (ed.) (en colaboración con Marín Martínez, T. y Martínez Díez, G., Madrid-Barcelona, 1963, 409.

${ }^{10}$ Ibidem, 257, 368 y 472.

11 Abad Casal, L., Gutiérrez Lloret, S. y Gamo Porras, B., "La basílica y el baptisterio del Tolmo de Minateda (Hellín, Albacete)", Archivo Español de Arqueología, 73 (2000), 193-221, y Gutiérrez Loret, S., Abad Casal, L. y Gamo Parras, "La iglesia visigoda de El Tolmo de Minateda (Hellín, Albacete)", Sacralidad y Arqueología. Thilo Ulbert zum 65 Geburtstag am Juni 2004 gewidmet, Blázquez, J. M. a y González Blanco, A. (eds.), apud Antigüedad y Cristianismo (Murcia) XXI (2004), 137-170.

Al-Qanțara (AQ) XXVII 2, julio-diciembre 2006, pp. 337-374 ISSN 0211-3589 
Por otro lado, las excavaciones han exhumado igualmente una fase islámica, que representa por el momento la última ocupación urbana del asentamiento, reflejada materialmente en la reforma de las fortificaciones, en la superposición de los cementerios y en la extensión de las estructuras urbanas emirales sobre las ruinas visigodas, hasta su abandono en un momento avanzado del siglo IX. Dicha trama urbana emiral - documentada en extensión sobre todo en la parte alta de la ciudad - se superpone con una evidente solución de continuidad a los escombros del edificio palatino, en cuyos muros destruidos apean ocasionalmente las nuevas estructuras, y a las ruinas de la antigua basílica por entonces totalmente enterrada, con excepción de algunos ambientes que fueron reempleados en las nuevas construcciones o bien quedaron como islotes relícticos en medio de los espacios abiertos (figs. 1b y 2).

La configuración de este extenso barrio ilustra una espectacular remodelación urbanística que afecta a una de las zonas públicas más emblemáticas de toda la ciudad visigoda; supone la secularización de un espacio urbano religioso, que ahora pasa a tener una función residencial y privada, y marca, con ese cambio de la vocación del suelo, la definitiva ruptura topográfica en este sector urbano. Su edificación, lejos de ser un acto espontáneo, parece consecuencia de una decisión planificada, que culmina el proceso previo de expolio sistemático, e incluye los trabajos de acondicionamiento de las ruinas, entre los que se cuentan el aterrazamiento y la construcción de márgenes de contención, o la nivelación que podría explicar el arrasamiento a una misma cota de los muros del edificio palatino. Esta planificación no significa en ningún caso que la estructura urbana resultante quedara inamovible durante toda su vida funcional; por el contrario, en muchos sectores del barrio encontramos indicios de reformas sucesivas que denotan cambios funcionales, con la desaparición de las áreas industriales del extremo oriental y una tendencia a la densificación de los espacios domésticos, patente en la división de algunas viviendas o en el adosamiento de otras para conformar estructuras más complejas, estudiadas recientemente ${ }^{12}$.

${ }^{12}$ Gutiérrez Lloret, S., "Madīnat Iyyuh y la destrucción del espacio urbano en la Alta Edad Media”, Castrum 8: El Castillo y la Ciudad. Espacios y redes (ss. VI-XIII) (Baeza, 2002), en prensa.

Al-Qanțara (AQ) XXVII 2, julio-diciembre 2006, pp. 337-374 ISSN 0211-3589 
FIGURA 2.-Barrio emiral superpuesto al complejo religioso visigodo

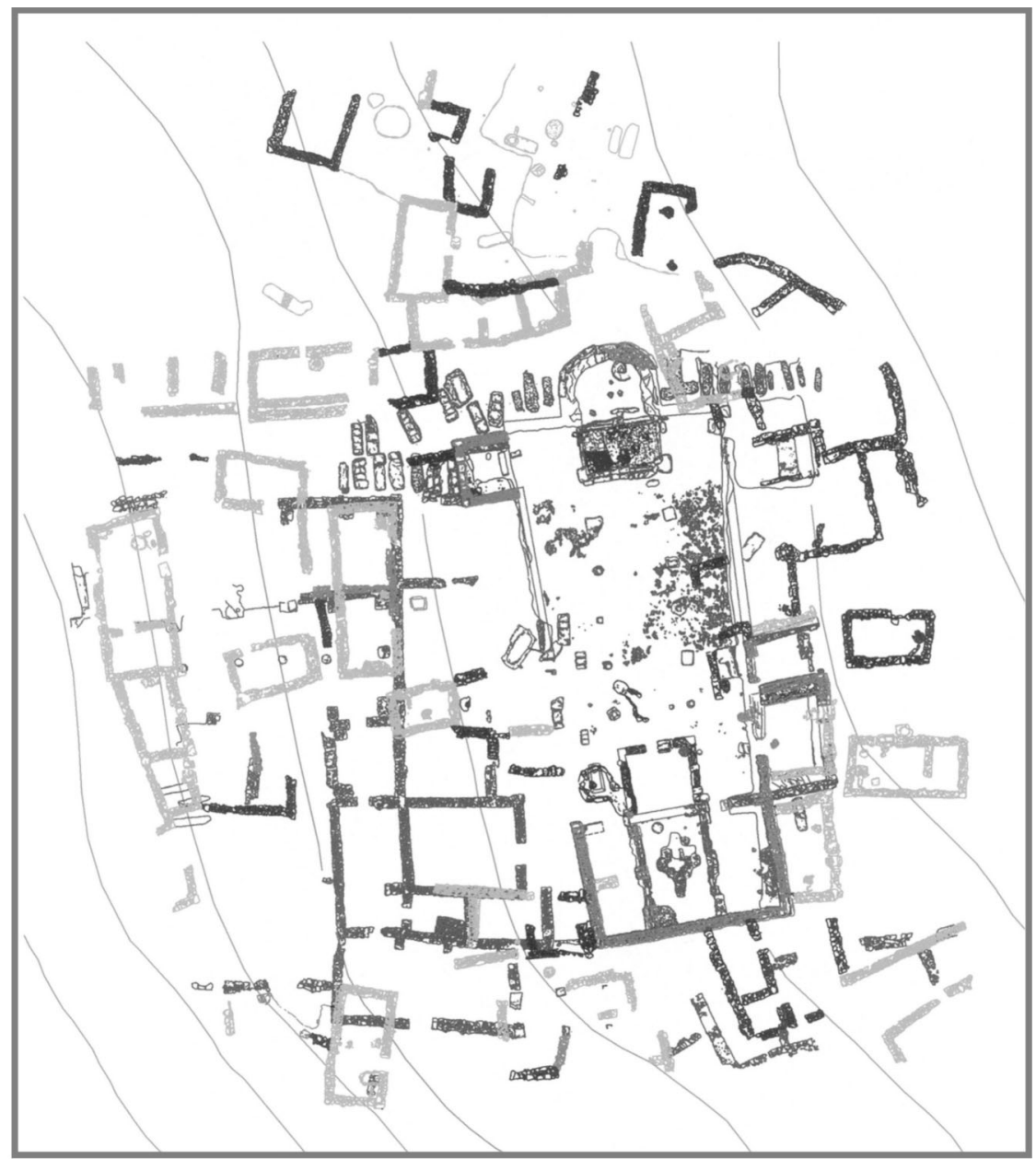

En términos generales puede afirmarse que esta remodelación comenzó a producirse en un momento indeterminado del siglo VIII y se prolongó a lo largo de la siguiente centuria, proporcionando un interesante conjunto de materiales correspondientes a época emiral. Con excepción de algunos ejemplos de superposiciones estructurales, que han permitido individualizar estratigráficamente algunos contextos emirales tempranos, el grueso de los ajuares domésticos corresponde 
a un horizonte plenamente emiral fechado en un sentido laxo en la segunda mitad del siglo IX ${ }^{13}$ y correspondiente al abandono definitivo del asentamiento en un momento avanzado del Emirato, a pesar de la pretendida destrucción ordenada por 'Abd al-Raḥmān II en una carta fechada el 27 de febrero del año 826, después de hacer de Murcia la sede de los gobernadores ${ }^{14}$.

Esta temprana fecha de destrucción no se corresponde con los vidriados monocromos de tipo baŷŷaní y la moneda emiral presentada en este mismo trabajo, que alargan la cronología de su abandono hasta la segunda mitad del siglo IX. La aparente contradicción emana seguramente de la distinta naturaleza de ambos registros documentales y parece denotar que el dato textual indica únicamente la voluntad política de restar importancia administrativa y probablemente fiscal a un centro urbano rebelde, marcando el inicio de un proceso de abandono que culminará ya muy avanzada la centuria. Esta disparidad se observa en otros ejemplos de aparentes «destrucciones» transmitidas por las fuentes escritas, como es el caso de la Cartagena bizantina a manos de los visigodos, donde los contextos cerámicos correspondientes a la destrucción del barrio del Teatro sugieren, a la luz de los hallazgos más recientes de Crypta Balbi y El Mahrine, fechas ligeramente más avanzadas que las estrictamente históricas ${ }^{15}$.

En los contextos de uso, abandono y destrucción de la fase emiral se ha documentado una serie de monedas, tanto islámicas como acu-

13 Gutiérrez Lloret, S., Gamo Parras, B. y Amorós Ruiz, V., "Los contextos cerámicos altomedievales del Tolmo de Minateda y la cerámica altomedieval en el sureste de la Península Ibérica", Cerámicas tardorromanas y altomedievales en la Península Ibérica: ruptura y continuidad, II Simposio de Arqueología (Mérida 2001), Anejos de Archivo Español de Arqueología, 28, 119-168.

${ }^{14}$ El texto de Ibn Hayyān del segundo volumen de Almuqtabis arroja nueva luz sobre las confusas referencias a la fundación de Murcia y a la destrucción de Iyyuh, que se relatan ahora como fenómenos no contemporáneos sino sucesivos, ordenados en dos misivas diferentes: la primera, fechada el 25 de junio del año 825, instando a Ŷābir b. Mālik a instalarse en Murcia y convertirla en sede de los gobernadores, y la segunda, del $27 \mathrm{de}$ febrero de 826, ordenando la destrucción de Iyyuh en la cora de Tudmīr (Ibn Hayyān, Crónica de los emires, 284). De esta forma se pone en entredicho la tradicional concatenación de ambos fenómenos, que sugería una ubicación próxima a la ciudad de Murcia, basada en el trasvase de la población de una a otra, y en detrimento de su emplazamiento en el Tolmo de Minateda, atestiguado por la referencia de al-'Udrī y la pervivencia toponímica.

${ }^{15}$ Ramallo Asensio, S.F. y Ruiz Valderas, H., "Cartagena en la arqueología bizantina, Hispania: estado de la cuestión", V Reunió d'Arqueologia Cristiana Hispànica (Cartagena, 1998), Barcelona, 2000, 305-321, 312-313.

Al-Qanțara (AQ) XXVII 2, julio-diciembre 2006, pp. 337-374 ISSN 0211-3589 
ñadas en períodos anteriores que, por su carácter contextualizado, proporcionan una visión novedosa de lo que fue la circulación monetaria de época emiral en esta ciudad. En este trabajo pretendemos presentar una primera aproximación a ese panorama, algo más pormenorizada que las referencias indirectas hasta ahora publicadas ${ }^{16}$, si bien todavía provisional, ya que parte del numerario está actualmente en proceso de limpieza, y discutir algunas implicaciones históricas, numismáticas y arqueológicas de dicho análisis.

\section{Las monedas de la ciudad}

La prolongada secuencia de hábitat del Tolmo de Minateda lo convierte en un lugar idóneo para estudiar la evolución del circulante a lo largo de diferentes períodos. Las numerosas campañas de excavaciones arqueológicas de que ha sido objeto han sacado a la luz una serie de vestigios que corroboran la importancia y significación histórica del yacimiento. En consonancia con el papel desempeñado por este enclave, encontramos un amplio repertorio numismático. Hasta el momento se han exhumado un total de 259 monedas que proceden de tres áreas diferentes de la ciudad: la necrópolis septentrional situada a los pies del cerro, el área de acceso a la ciudad conocida como el Reguerón, y, sobre todo, la zona alta donde se ubica el complejo episcopal visigodo y más tarde el barrio emiral. Esta última área es la que presenta una superficie excavada más extensa y de donde procede la mayor parte del material numismático recuperado. La cronología de los materiales numismáticos es amplia, ya que contamos con numerario de todos los períodos históricos, desde momentos prerromanos

16 Referencias al numerario emiral pueden verse en Doménech Belda, C., "Los estudios de circulación monetaria en la numismática andalusí: el caso del País Valenciano", IV Jarique de Numismática Andalusí, (Jaén, 2000), Canto García, A. y Salvatierra Cuenca, V. (eds.), Jaén, 2001, 53-79, y Dinares, dirhames y feluses. Circulación monetaria en el País Valenciano, Alicante, 2003; Doménech Belda, C. y Gutiérrez Lloret, S., "Las monedas del Tolmo de Minateda, Hellín (Albacete)", XIII Congreso Internacional de Numismática, en prensa; Gutiérrez Lloret, S., Gamo Parras, B. y Amorós Ruiz, V., "Los contextos cerámicos", y Gutiérrez Lloret, S., "Cerámica y escritura: dos ejemplos de arabización temprana. Graffiti sobre cerámica del Tolmo de Minateda (Hellín, Albacete)", Arqueología Medieval (Homenaje a Juan Zozaya, Mértola, 2005), en prensa, y "Madīnat Iyyuh y la destrucción".

Al-Qanțara (AQ) XXVII 2, julio-diciembre 2006, pp. 337-374 ISSN 0211-3589 
hasta época contemporánea, aunque con notables diferencias cuantitativas entre ellos (Cuadro 1).

CuAdro 1.-Distribución por series de las monedas del Tolmo

\begin{tabular}{|c|c|c|}
\hline SERIE & N. ${ }^{\circ}$ EJEMPLARES & $\%$ \\
\hline 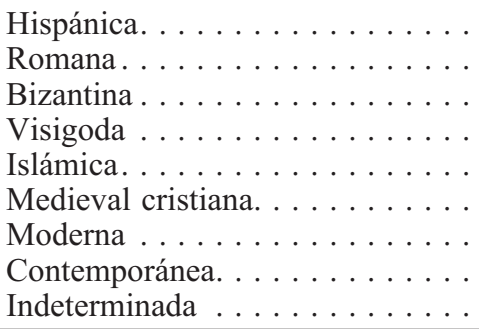 & $\begin{array}{r}6 \\
148 \\
1 \\
6 \\
19 \\
2 \\
1 \\
9 \\
67\end{array}$ & $\begin{array}{r}2,32 \\
57,14 \\
0,39 \\
2,32 \\
7,33 \\
0,77 \\
0,39 \\
3,47 \\
25,87\end{array}$ \\
\hline TOTAL $\ldots \ldots \ldots \ldots$ & 259 & 100 \\
\hline
\end{tabular}

Los ejemplares más antiguos, entre los que se encuentran tanto monedas hispánicas como ases romanos de tipo Jano bifronte, datan del siglo II a. C. El circulante romano es precisamente el más abundante en el yacimiento ${ }^{17}$ y quizá el más significativo, dados los contextos en los que aparece. No obstante y como veremos más adelante, este numerario romano es muy desigual a lo largo de las centurias.

Se ha documentado también un pequeño bronce bizantino con valor de cuatro nummi de la serie cruz/delta, identificada por M. Lechuga ${ }^{18}$ como una emisión local de Cartago Spartaria, único lugar en que hasta ese momento había sido localizado este tipo de piezas. El hallazgo del ejemplar del Tolmo, junto con dos más, procedentes de Me-

17 Existe un número importante de piezas pendientes de restauración que probablemente puedan ser identificadas como romanas, pero, como su estado actual no permite precisarlo, se ha preferido agruparlas bajo el epígrafe de indeterminadas. Pese a ello, el porcentaje de circulante romano es muy superior al del resto de los períodos.

${ }^{18}$ Lechuga Galindo, M., "Una aproximación a la circulación monetaria de época tardía en Cartagena: los hallazgos del teatro romano", V Reunió d'Arqueologia cristiana Hispànica (Cartagena 1998), Barcelona, 2000, 333-349, y Lechuga Galindo, M. y Méndez, R., "Numismática bizantina de Cartagena", Historia de Cartagena, Murcia, 1991, VI, $72-78$

Al-Qanțara (AQ) XXVII 2, julio-diciembre 2006, pp. 337-374 ISSN 0211-3589 
norca, empieza a insinuar la expansión comercial de la capital imperial ${ }^{19}$. Estos pequeños bronces bizantinos han sido datados por contextos arqueológicos entre la segunda mitad del siglo VI e inicios del siglo VII d. C.

De la Alta Edad Media, el período mejor representado por la entidad y extensión de sus restos arqueológicos, contamos con seis trientes visigodos datados todos ellos en los últimos años del siglo VII e inicios del VIII d. C., y diecinueve monedas islámicas de cronología emiral. La serie se completa con tres monedas de época medieval cristiana y una moderna, todas ellas localizadas a los pies del cerro en una zona de camino, a más de varias contemporáneas que se explican por la ubicación de un conjunto de viviendas semirrupestres en las laderas del cerro durante el siglo XX. La aparición de numerario correspondiente a las fases en que el asentamiento perdió su carácter urbano y devino en venta caminera, confirma la importancia del enclave como punto destacado en el viario, que mantuvo hasta hace pocos años.

El conjunto mejor representado en el numerario del Tolmo corresponde al período romano, que supone el 57 por 100 de las piezas catalogadas. Dentro de este alto porcentaje se ocultan grandes diferencias de unas centurias a otras, destacando claramente las monedas del Bajo Imperio, que acaparan más del 62 por 100 de los ejemplares romanos, y sobre todo, las correspondientes al siglo IV d. C. que forman el grupo más numeroso (Gráfico 1).

Por esta razón, si atendiéramos exclusivamente a la cronología intrínseca de las monedas, sin mayores argumentos arqueológicos, podríamos afirmar que El Tolmo de Minateda fue una pujante ciudad durante los siglos III y IV de nuestra era. Sin embargo, la evidencia arqueológica nos indica todo lo contrario: a partir de un momento indeterminado del siglo II d. C., la ciudad entró en un proceso de decadencia en beneficio del valle circundante, que vio proliferar asentamientos rústicos donde se localizan en abundancia los vestigios materiales de los siglos III y IV d. C. que, por el momento, están au-

19 La moneda del Tolmo fue publicada por nosotras mismas en las actas del XIII Congreso Internacional de Numismática (Doménech Belda, C. y Gutiérrez Lloret, S., "Las monedas del Tolmo"). Las dos piezas de Menorca han sido publicadas recientemente por Moll Mercadal, B., 'L'Imperi Romà d'Orient a Menorca: el testimoni numismàtic”, Gaceta Numismática, 157 (2005), 5-44, 13 y 33.

Al-Qanțara (AQ) XXVII 2, julio-diciembre 2006, pp. 337-374 ISSN 0211-3589 
GrÁFICO 1.-Distribución de la moneda romana por centurias

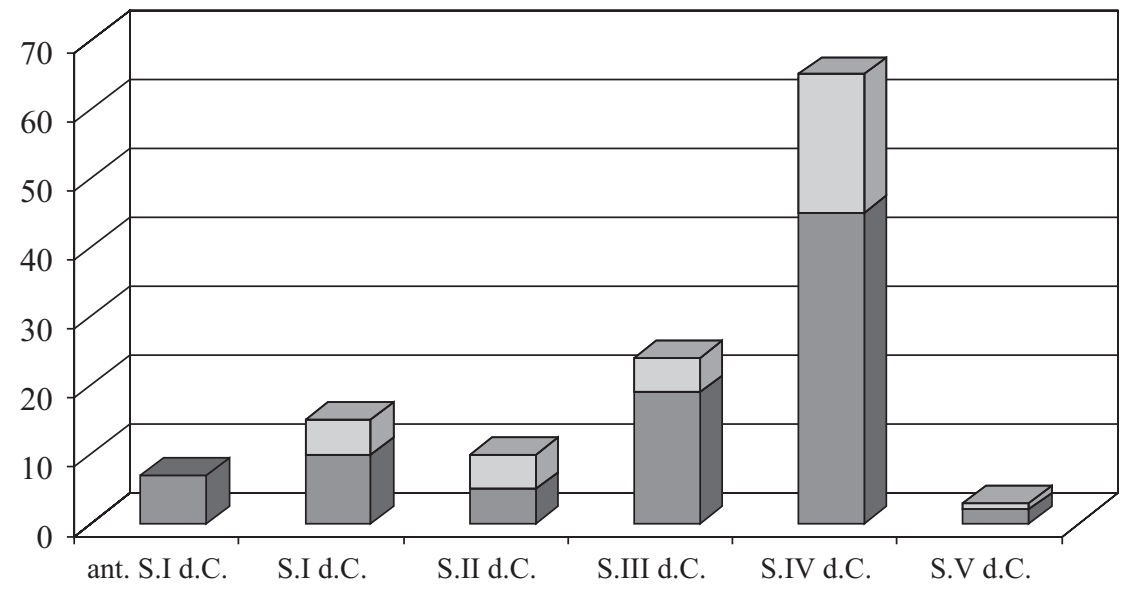

sentes en el cerro ${ }^{20}$. Si, por el contrario, tomamos en consideración el contexto arqueológico en el que han aparecido las monedas, la relación entre fecha de acuñación y momento de circulación se muestra más distante de lo que a priori cabría suponer.

Casi el 90 por 100 de los hallazgos monetarios del Tolmo de Minateda se encuentran en contextos estratigráficos fiables, lo que permite plantear algunas cuestiones relevantes y obtener información muy valiosa referida a la circulación monetaria de época visigoda y emiral en una ciudad cuya importancia histórica ponen de manifiesto sus propios restos arqueológicos. El estudio de las monedas en su contexto de uso permite detectar y comprobar pervivencias en el numerario, que ya se insinúan por el grado de desgaste que presentan las piezas y que en el caso de los cobres bajoimperiales vamos conociendo cada vez mejor.

${ }^{20}$ En estos diecisiete años de excavaciones arqueológicas sistemáticas no hemos documentado contextos constructivos o de uso correspondientes a los siglos III, IV y V d. C. en ninguno de los sectores excavados, a diferencia de lo que ocurre, por ejemplo, con los restos de la Edad del Bronce o de época ibérica. El análisis conjunto de toda la Terra Sigillata residual hallada en las excavaciones y procedente mayoritariamente de los contextos altomedievales, muestra igualmente una rarefacción de las producciones correspondientes a dicho período, que confirma la impresión estratigráfica del significativo hiato poblacional entre los siglos II y VI, fecha de la reviviscencia urbana visigoda. Agradecemos los datos inéditos sobre la cerámica romana a Antonio Espinosa Ruiz y Gabriel Lara Vives.

Al-Qanțara (AQ) XXVII 2, julio-diciembre 2006, pp. 337-374 ISSN 0211-3589 
Estas monedas romanas, y también otras de cronologías más antiguas, aparecen con frecuencia en El Tolmo en niveles visigodos e islámicos, en los que también encontramos monedas de esos períodos aunque en cantidades bastante inferiores. Indudablemente, el análisis conjunto de las monedas de un mismo contexto urbano de uso, independientemente del momento de su acuñación, nos da una visión distinta de la circulación monetaria de esta ciudad emiral.

\section{El numerario islámico}

La presencia de moneda islámica en una ciudad emiral no debe parecer, en principio, nada extraño. Sin embargo, durante mucho tiempo se había observado que la moneda islámica estaba ausente de los yacimientos andalusíes ${ }^{21}$. Nosotras mismas apuntábamos hace ya algunos años este hecho en referencia al mismo yacimiento que ahora tratamos ${ }^{22}$. La continuidad y extensión de las excavaciones en el cerro ha demostrado que el registro numismático no sólo existía, sino que era considerable. En total se han recuperado diecinueve monedas, todas ellas de cronología emiral, que se concretan en diez feluses y nueve dírhams entre piezas enteras y fragmentos ${ }^{23}$. La mayor parte de

${ }^{21}$ Hasta hace pocos años era comúnmente admitido que el número de monedas árabes que aparecían en el transcurso de trabajos arqueológicos era muy escaso o nulo como apuntaba entre otros Guichard, P., Les musulmans de Valence et la reconquête (XI-XIII siècles), Damasco, 1990, n. 35. De hecho, en esa misma línea, una de nosotras apuntaba que existe un gran número de yacimientos arqueológicos prospectados que no han proporcionado ninguna moneda (Doménech Belda, C., Dinares, dirhames, 20). No obstante, si bien es cierto que difícilmente encontramos monedas árabes en los yacimientos únicamente prospectados, no lo es menos que las excavaciones cada vez más numerosas de yacimientos andalusíes realizadas en la actualidad permiten matizar dicha afirmación.

22 En el año 2000, a propósito del valor cronológico de la moneda y a tenor de los datos numismáticos del año 1999 en El Tolmo, todavía una de nosotras afirmaba que durante más de una década de "[...] ...excavación sistemática y en extensión de importantes niveles altomedievales, las relativamente escasas monedas aparecidas en contextos visigodos y emirales son casi siempre romanas, correspondiendo generalmente a tipos de bronce de los siglos II a IV d. C., no habiéndose hallado ninguna moneda visigoda y sólo un fals emiral" (Gutiérrez Lloret, S., "Algunas consideraciones sobre la cultura material de las épocas visigoda y emiral en el territorio de Tudmīr", Visigodos y Omeyas (Mérida, 1999), Anejos de Archivo Español de Arqueología, XXIII (2000), 95-116, en 97-8, n. 7). A la vuelta de cinco años de trabajo sistemático el panorama numismático altomedieval ha variado sensiblemente.

${ }^{23}$ Muy probablemente, una vez finalizado el proceso de limpieza y restauración de los materiales se puedan identificar como islámicas algunas piezas más, que, por su as-

Al-Qanțara (AQ) XXVII 2, julio-diciembre 2006, pp. 337-374 ISSN 0211-3589 
ellas (quince ejemplares) procede de distintos puntos de la zona alta de la ciudad, ocupada por un barrio de viviendas islámicas construido sobre el conjunto episcopal visigodo ya amortizado (fig. 2). Las cuatro restantes provienen del Reguerón, vaguada natural que da acceso a la parte alta de la ciudad. Todo este numerario ha aparecido disperso en ámbitos diferentes de la ciudad, lo que indica que se trata de pérdidas casuales, sin que se aprecie en ningún caso intencionalidad alguna de ocultación. Lo mismo sucede con el resto del circulante que hemos adscrito a otros períodos: todo él ha sido localizado en forma de piezas aisladas, a excepción de cuatro trientes visigodos acuñados a nombre de Witiza que aparecieron juntos en el espacio abierto situado entre el palatium y la basílica, en concreto cerca de su entrada monumental septentrional ${ }^{24}$ (fig. 3a).

\section{La problemática de los cobres}

De todos es sabido que la moneda de cobre presenta dentro de la numismática andalusí una problemática peculiar debido, entre otras cosas, a su alto grado de variabilidad formal y metrológica que contrasta fuertemente con la homogeneidad de las acuñaciones de plata; al hecho de carecer con frecuencia de mención de ceca y fecha, lo que dificulta notablemente su adscripción cronológica a un taller determinado, $\mathrm{y}$ al olvido tradicional que han sufrido por la investigación a consecuencia de los problemas antedichos. Afortunadamente, el panorama está cambiando, como lo demuestra la aparición de trabajos dedicados al estudio de estos feluses ${ }^{25}$, aunque a pesar de ello siguen planteando numerosos interrogantes.

pecto, parecen serlo y que ahora figuran en el apartado de indeterminadas porque su estado actual no permite afirmarlo.

${ }^{24}$ Las cuatro monedas aparecieron próximas en la misma unidad estratigráfica (61.838) pero sin trazas de constituir una ocultación propiamente dicha. El estrato contenía diversos materiales visigodos, además de algunos fragmentos probablemente islámicos; se trata de un estrato claramente posterior a la construcción y uso original del palatium, pero previo al urbanismo islámico propiamente dicho, que parece relacionarse con otros usos del siglo VIII que ocupan ciertos ambientes del edificio palatino todavía en pie, al tiempo que otros — en especial los más amplios, como el aula palatina — ya se hallan parcialmente arruinados; todos ellos serán obliterados y probablemente alterados por la construcción del arrabal islámico superpuesto.

25 Sirvan como ejemplo los trabajos de Frochoso, R., "Los feluses del período de los gobernadores omeyas en al-Andalus", Numisma, 237 (1996), 259-289, y Los feluses de 
FIGURA 3.-Localización de los hallazgos monetarios en contextos previos al barrio islámico

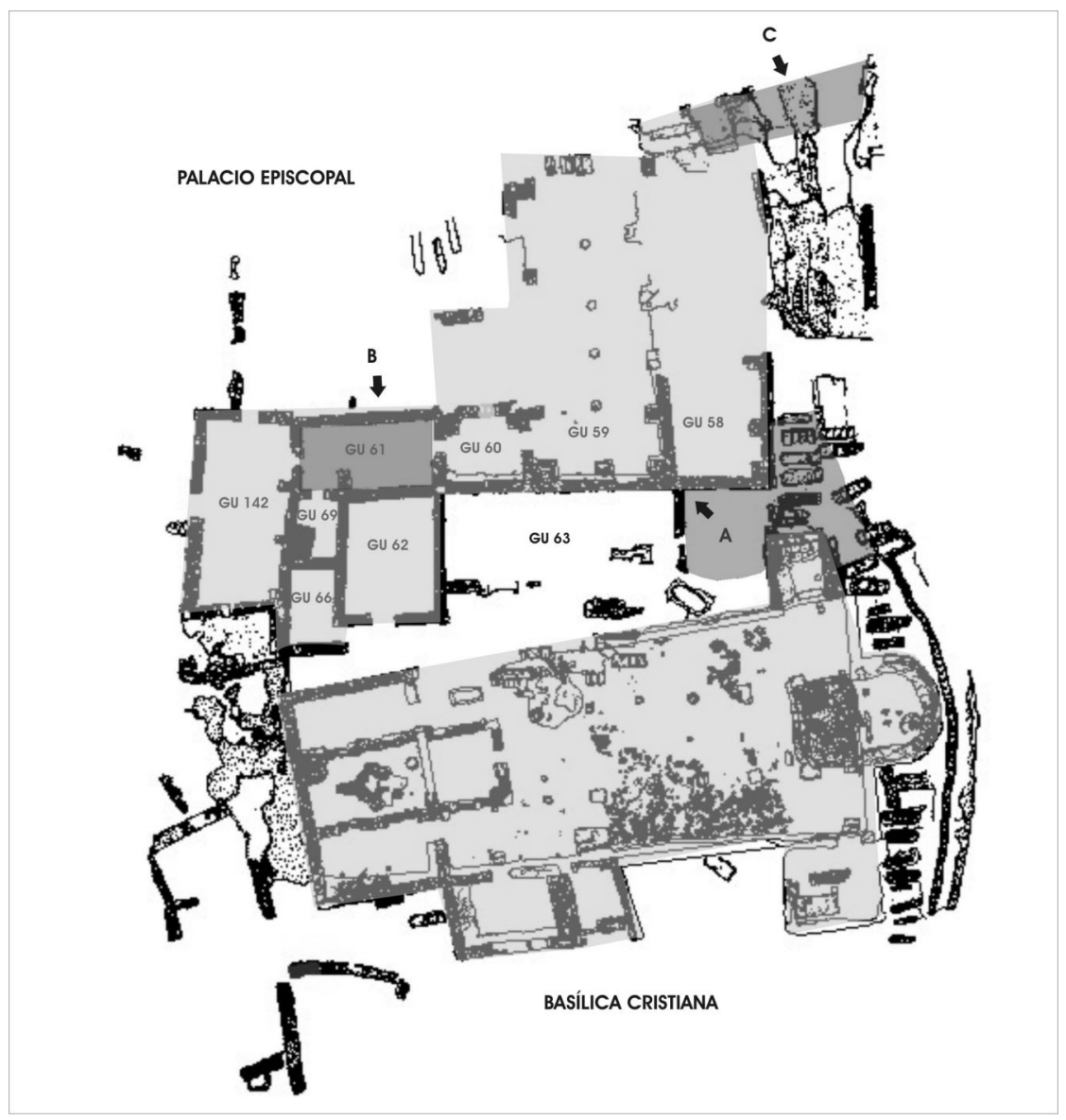

Estamos convencidas de que una vía de investigación, y tal vez la única, que puede aportar algo de luz al estudio de los feluses y a la problemática histórica del período a que van asociados - la conquista de al-Andalus y el Emirato-, es la de contextualizar los hallazgos.

al-Andalus, Córdoba, 2001; o el de Doménech Belda, C., "Circulación monetaria de época emiral en el País Valenciano: el problema de las primeras emisiones en cobre", Congreso Nacional de Numismática, Elche, 1994, 281-302.

Al-Qanțara (AQ) XXVII 2, julio-diciembre 2006, pp. 337-374 ISSN 0211-3589 
Para ello es necesario estudiarlos en relación con el lugar en que aparecen, atendiendo a la posición estratigráfica que ocupan dentro de la secuencia general, y poniéndolos en relación con los restantes materiales arqueológicos; en suma, se trata de ubicarlos en la secuencia «cronoespacial» donde fueron depositados o perdidos. De esta forma, no sólo tendremos una información más completa, sino que podremos ir delimitando períodos de circulación, pervivencias, áreas de dispersión del numerario y un largo etcétera de cuestiones que sólo se pueden abordar a través de la contextualización del numerario.

La mayor parte del circulante de la ciudad emiral del Tolmo estaba formada por monedas de cobre. Algunas eran viejos cobres romanos, mayoritariamente de los siglos III y IV d. C.; otros, más modernos, eran los acuñados con leyendas árabes que conocemos como feluses. Algunos de estos feluses fueron exhumados entre los derrumbes de las viviendas de la segunda fase del barrio emiral, en pleno siglo IX, e incluso han aparecido en limpiezas superficiales sin fiabilidad estratigráfica alguna, como es el caso de un pequeño fragmento reducido prácticamente a una porción de orla $\left(\mathrm{n}^{\mathrm{o}}{ }^{\mathrm{1}} 10\right)^{26}$.

Sin embargo, en otros ejemplos los contextos estratigráficos nos sitúan en momentos más antiguos y fiables. Es el caso de los feluses hallados en un área doméstica islámica situada al sur de la basílica junto al muro meridional del baptisterio y sobre la estancia aneja al mismo ${ }^{27}$ (figs. 4a y 5). El que ocupa la posición estratigráfica más antigua es un felús (n. $\left.{ }^{\circ} 1\right)$ con leyendas religiosas dispuestas en dos líneas de escritura en cada área: en la primera figura la primera parte de la profesión de fe islámica y en la segunda la misión profética de Mahoma con un adorno en forma de ángulo situado entre las dos líneas. Carece de leyendas marginales y por tanto de ceca y fecha. Sus caracteres epigráficos y metrológicos hacen pensar en una acuñación temprana y, de hecho, este tipo de feluses se viene considerando del período de los Gobernadores ${ }^{28}$ en base a dichas características. A estos criterios pura-

\footnotetext{
${ }^{26}$ Este felús fue recuperado en las tareas de limpieza de las carriladas del camino de acceso a la ciudad. Conserva parte de la fecha y posiblemente se trate de uno de los tipos atribuidos al emir Muhammad I.

27 Se trata del espacio ocupado por los grupos de unidades 6 y 8/9, dos ambientes domésticos separados por un azucate (7).

28 Todavía actualmente se siguen utilizando como criterio de distinción, por carecer de otros, tanto el aspecto tosco de las piezas como las leyendas breves o el diámetro reducido unido a un grosor considerable, mientras que los que presentan leyendas más largas,
} 
mente estilísticos podemos añadir ahora la argumentación estratigráfica, que confirma plenamente la presencia de los feluses de estas características - sin datar y con leyendas exclusivamente religiosas - en el circulante andalusí de los primeros momentos.

El felús fue exhumado en un estrato (UE 60295) formado por la destrucción de las tapias de tierra anaranjada de un edificio construido a finales del siglo VII al oeste del baptisterio, utilizado posteriormente como cementerio infantil ad sanctos, y parcialmente expoliado y destruido en un momento indeterminado del siglo VIII; este estrato, formado necesariamente en un momento avanzado de dicho siglo (contemporáneo o posterior a la moneda que contiene), fue recortado durante las obras de construcción del barrio islámico para edificar en concreto la casa 6, adosada al viejo muro sur, ahora reempleado, del baptisterio y abierta a un patio delantero (figs. 4a y 5). En consecuencia, la moneda constituye el límite post quem de la erección de dicho arrabal, que no pudo ser por tanto - al menos en este sector meridional- anterior a mediados del siglo VIII; sabiendo además que el abandono de dicho barrio se produjo en un momento indeterminado, pero posiblemente avanzado, de la segunda mitad del siglo IX, aunque sin alcanzar el Califato.

En la misma zona del yacimiento pero situado en un estrato datado con posterioridad al anterior, apareció un felús (n. $\left.{ }^{\circ} 2\right)$ que presenta en una de sus caras el nombre de la ceca "بالاندلس" en posición central y restos de la leyenda de la orla. El centro de la otra área lo ocupa una estrella que apenas se aprecia, en parte por el desgaste que sufre la moneda, en parte debido a que el cuño está considerablemente desplazado del centro del cospel por lo que resulta imposible conocer el número de puntas que la forman ${ }^{29}$. También en esta área figura parte de una leyenda de orla, que en otros ejemplares no aparece. Se trata de la leyenda religiosa الا اله الا الله (وحده) محمد رسول اللها》. Este tipo de feluses fue acuñado indudablemente en tierras andalusíes pues así se resalta en las propias piezas, donde la mención de la ceca ocupa el espa-

mayor diámetro y menor grosor se consideran acuñados por los emires omeyas. Pero lo cierto es que existe un gran número de feluses que presentan características de uno y otro grupo que aún hoy son de dudosa atribución.

${ }_{29}$ La estrella puede ser de 6,7 u 8 puntas. El símbolo de la estrella también se encuentra en algunas fracciones de dinares acuñadas en tiempos de la conquista y se ha interpretado como el lucero de poniente, que vendría a significar las acuñaciones andalusíes.

Al-Qanțara (AQ) XXVII 2, julio-diciembre 2006, pp. 337-374 ISSN 0211-3589 
FIGURA 4.-Localización de los principales hallazgos de moneda islámica en el barrio emiral (áreas A, B y C)

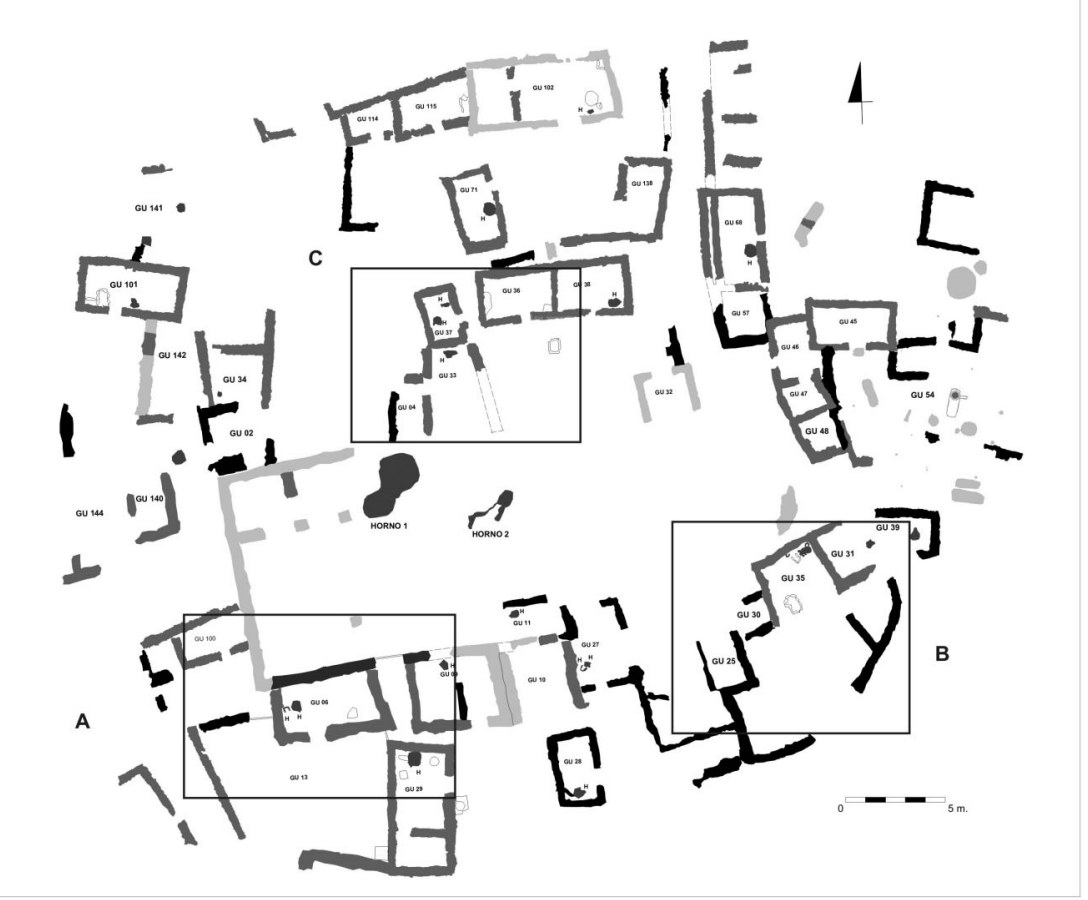

cio central del campo de la moneda como continuación de la leyenda marginal, pero carece de fecha. Sin embargo, estos feluses con estre1la han sido considerados tradicionalmente de los más antiguos, llegando a ser, en opinión de A. Medina ${ }^{30}$, los primeros que se acuñaron. Sus características metrológicas con pesos y grosores altos apoyan la datación temprana de este grupo de feluses.

La pieza apareció en el desmonte de la esquina meridional del muro occidental de la casa 8, separada de la 6 por un estrecho pasillo y contemporánea a la misma (figs. 4a y 5). Su hallazgo en el interior del muro fecha la estructura doméstica en época emiral, lo que, unido al hallazgo anterior, confirma la cronología islámica de la remodelación urbana. En esta misma zona, si bien en un contexto menos fiable,

${ }^{30}$ Monedas hispano-musulmanas, Toledo, 1992, 86. 
Figura 5.-Planta y sección del contexto arqueológico de las monedas $n .^{\circ} 1,2$ y 4

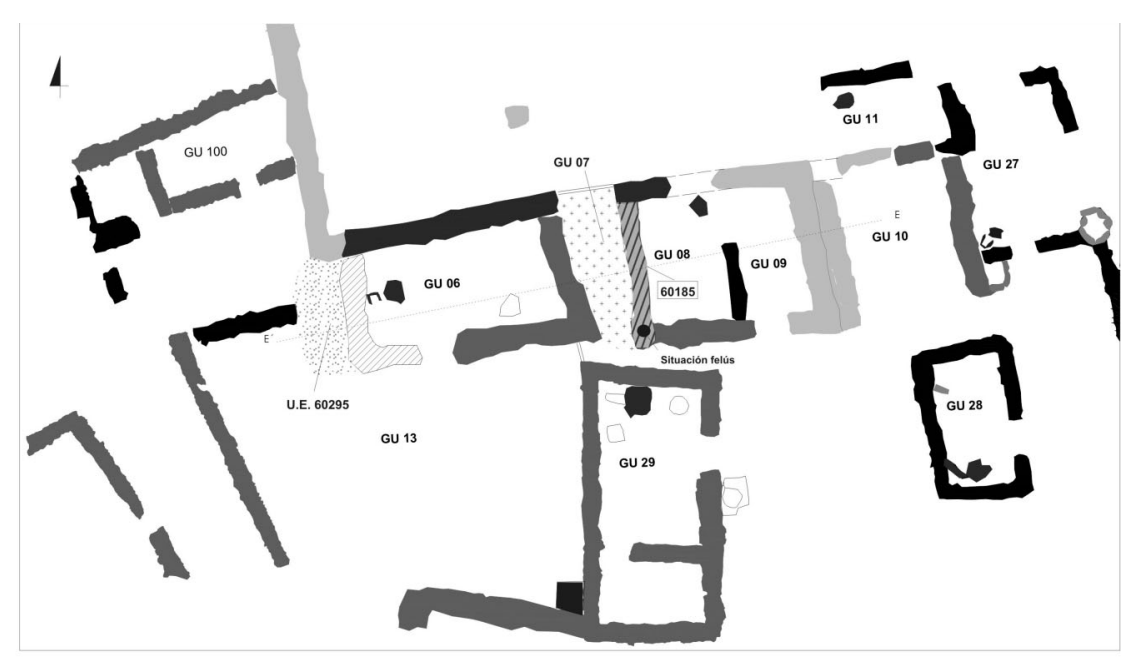

A

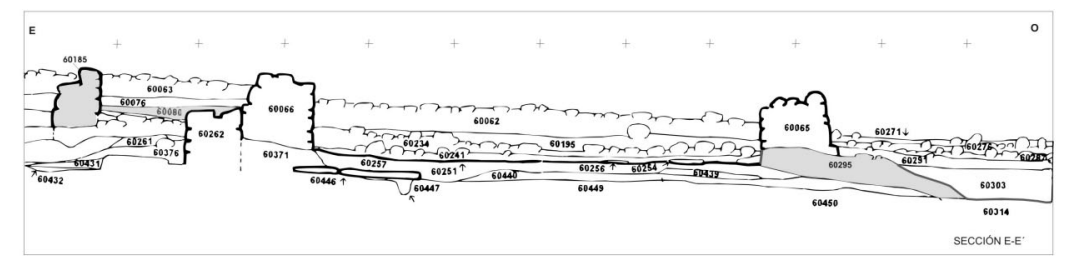

B

fue hallado un tercer felús ${ }^{31}$ que, al igual que los dos anteriores, presenta un diámetro reducido y grosor considerable (n. $\left.{ }^{\circ} 4\right)$. Estos tres feluses parecen presentar una fecha de acuñación bastante temprana dentro del período emiral, ya sea en base a sus características metrológicas y formales como por su situación estratigráfica dentro del

31 Se trata de un hallazgo casual en el marco de una visita, en la superficie de los estratos de circulación del pasillo 7 , situado entre las casas 6 y $8 / 9$, de donde proceden respectivamente los feluses antedichos.

Al-Qanțara (AQ) XXVII 2, julio-diciembre 2006, pp. 337-374 ISSN 0211-3589 
conjunto, que nos está sugiriendo una probable y significativa homogeneidad temporal de las tres piezas.

Otra moneda que consideramos interesante y que ha sido de gran ayuda a la hora de datar unos usos de difícil caracterización ceramológica, es un felús de aspecto tosco que presenta un elevado peso (n. $\left.{ }^{\circ} 3\right)$. Aunque su estado de conservación no permite por completo su lectura, parece apreciarse en la parte superior de una de las áreas el final de la palabra Muhammad y la «J» de rasūl en letras de tamaño tan considerable que, a pesar de que el módulo de la moneda supera los diecinueve milímetros, el inicio de la frase ha quedado fuera del cospel. En la otra área sólo se intuyen muy vagamente algunos trazos de la leyenda por lo que, por el momento ${ }^{32}$, resulta difícil adscribirlo a ningún tipo concreto, si bien el estilo de la pieza recuerda a los feluses norteafricanos. No obstante y con independencia de la adscripción tipológica de la moneda, la exhumación de este felús en un estrato interpretado como una posible repavimentación de ciertas habitaciones del palatium para un uso distinto del prístino, ha permitido datar con certeza en el siglo VIII los conjuntos cerámicos procedentes de los niveles de abandono y destrucción situados entre dichos suelos y los niveles de construcción del barrio islámico (fig. 3b).

Este hallazgo confirma la impresión tipológica que nos hacía suponer una datación islámica temprana (siglo VIII) para dichos contextos, al tiempo que la composición de los ajuares (abundan las marmitas y el material culinario) permite suponer la readaptación de ciertos ambientes palatinos a un uso doméstico, atestiguado por otro lado en ciertas estancias de la basílica ${ }^{33}$. Al igual que ocurría en este edificio religioso, la evidencia estratigráfica situaba claramente estas fases en un momento posterior a la erección de los edificios visigodos y previo a la construcción del barrio emiral entre mediados o finales del siglo VIII y primera mitad del IX, pero dejaba abierta su ubicación en un momento visigodo o ya plenamente islámico. La aparición de este felús parece inclinar definitivamente la balanza hacia el siglo VIII y materializa por vez primera la reutilización doméstica del complejo monumental visigodo con posterioridad a la conquista. La contextua-

\footnotetext{
32 Una vez finalizado el proceso de limpieza y restauración de la pieza tal vez podamos obtener una lectura más completa.

33 Gutiérrez Lloret, S., Gamo Parras, B. y Amorós Ruiz, V., "Los contextos cerámicos", 140 y ss.
} 
lización de la moneda permite, en este caso, reconocer con certeza cronológica los hasta ahora evanescentes repertorios cerámicos del siglo VIII.

Un último ejemplo de cobre contextualizado lo constituye un felús (n. ${ }^{\circ} 6$ ) con leyenda marginal donde figura una fecha temprana, el año 108 h./726-7 J. C. La moneda fue hallada en el nivel de abandono/destrucción de uno de los espacios domésticos islámicos más modernos de la parte baja de la ciudad, en las inmediaciones de la puerta principal. En este sector pudo documentarse una larga secuencia de ocupación caracterizada, en lo que a las fases altomedievales se refiere, por la erección de un baluarte defensivo visigodo, coronado por un espacio doméstico de la misma cronología ${ }^{34}$. Tras varias fases de uso, fechables entre la segunda mitad del siglo VII y principos del VIII, y ante la obsolescencia de la fortificación visigoda, este sector fue obliterado, para construir sobre él una nueva muralla - en rigor, una simple albarrada de tierra - contra la que se fueron apoyando sucesivas fases de hábitat, siendo la del felús la más moderna. Este hallazgo confirma la adscripción estratigráfica de la muralla y los usos sucesivos a ella asociados a la época islámica.

\section{La moneda de plata}

Además de la moneda de cobre, durante el período emiral se acuñan dírhams de plata que, ante la ausencia de emisiones áureas, se convierten en este momento en la moneda de mayor valor del sistema monetario andalusí. Es la moneda fiscal con la que el estado emiral hace sus pagos y cobra sus impuestos. Su alto valor de mercado en los primeros siglos del islam andalusí explica la práctica de fragmentar las piezas para obtener moneda fraccionaria, práctica que se generaliza en época califal donde se explica fácilmente por el abandono de la acuñación de feluses. Pero, sin duda, la fragmentación de los dírhams

\footnotetext{
${ }^{34}$ Gutiérrez Lloret, S., "El espacio doméstico altomedieval del Tolmo de Minateda (Hellín, Albacete), entre el ámbito urbano y el rural", Castrum 6. Maisons et espaces domestiques dans le monde Méditerranéen au Moyen Âge (Erice-Trappani, 1993), Roma-Madrid, 2000, 151-164; Gutiérrez Loret, S. y Abad Casal, L., "Fortificaciones urbanas altomedievales del Tolmo de Minateda (Hellín, Albacete, España): el baluarte occidental", Mil Anos de Fortificaçôes na Península Ibérica e no Magreb (500-1500); Actas do Simpósio Internacional sobre Castelos, Lisboa, 2002, 133-143.
}

Al-Qanțara (AQ) XXVII 2, julio-diciembre 2006, pp. 337-374 ISSN 0211-3589 
se inicia en época emiral a pesar de que los cobres, tanto árabes como romanos, circulaban con profusión, por lo menos en el asentamiento que nos ocupa.

En El Tolmo se han exhumado nueve dírhams, todos ellos fragmentados ex profeso a excepción de uno que es el único que no es andalusí (n. $\left.{ }^{\circ} 11\right)$. Si nos atenemos a los pesos de estos fragmentos comprobamos la tendencia a concentrarse en valores que corresponderían a un cuarto y un octavo de dírham, considerando que el peso teórico de un dírham sin alteraciones se situaría entre 2,65 y 2,70 g. ${ }^{35}$, tendencia constatada en algunos conjuntos emirales con una importante presencia de fragmentos ${ }^{36}$ (Gráfico 2).

GRÁFICO 2.-Frecuencia de pesos de los fragmentos de dírhams (en el eje horizontal figuran los pesos, en gramos, y en el vertical, el número de monedas)

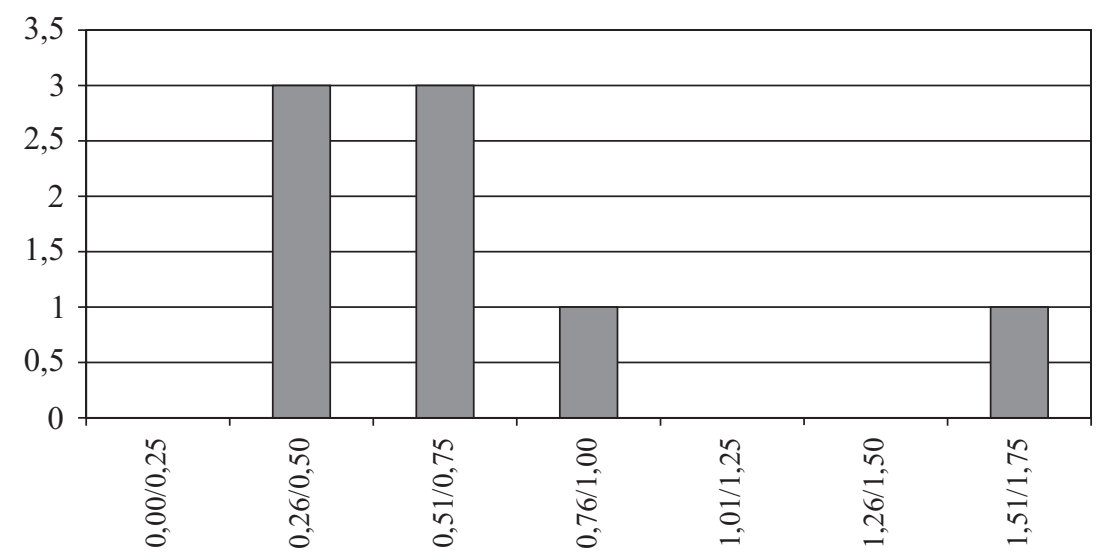

35 Sobre los aspectos metrológicos en el Emirato véase Canto García, A. y Marsal Moyano, E., "On the metrology of the silver coinage of the Spanish Amirate", Problems of Medieval Coinage in the Iberian Area 2, Avilés, 1986, 167-180.

${ }^{36}$ Por ejemplo, los hallazgos de Iznájar donde los fragmentos suponen el 34 por 100 de las piezas (Canto García, A. y Marsal Moyano, E., "Hallazgo de moneda emiral de Iznájar (Granada)", Al-Qanțara, IX, 2 (1998), 427-470; o el de Puebla de Cazalla en el que llegan a alcanzar un porcentaje del 70 por 100 (Ibrahim, T. y Canto, A., "Hallazgo emiral de Puebla de Cazalla (Sevilla)", Numisma, 229 (1991), 69-86).

Al-Qanțara (AQ) XXVII 2, julio-diciembre 2006, pp. 337-374 ISSN 0211-3589 
Salvo un ejemplar de gran tamaño que conserva aproximadamente las tres cuartas partes de la pieza (n. $\left.{ }^{\circ} 12\right)$, el resto son fragmentos más pequeños cuyos pesos no siempre se corresponden con su aspecto formal. Dos de ellos son porciones de reducido tamaño: una sería en origen un fragmento de un cuarto de pieza que luego volvería a ser cercenada, quedándose en algo más que un fragmento de orla (n. $\left.{ }^{\circ} 18\right)$; la otra es un fragmento todavía menor, que sólo alcanza los 0,2 g. de peso (n. $\left.{ }^{\circ} 19\right)$. Los cinco fragmentos restantes (n..$^{\circ} 13$ a 17) corresponden claramente a un cuarto de dírham perfectamente reconocible, con cortes cuidados que dejan bordes dentados o lisos según los casos y, en ocasiones, en la misma pieza, como sucede con un fragmento correspondiente al cuadrante inferior derecho de un dírham (n. $\left.{ }^{\circ} 14\right)$, donde el corte superior ha sido practicado de forma cuidada dejando el borde de la pieza completamente liso, mientras que la fragmentación del lateral izquierdo de la pieza ha dejado un borde dentado. Da la impresión de que el dírham fue cortado por la mitad desde el anverso, separando la leyenda de dicha cara en una mitad superior y otra inferior, para, en un momento posterior, o al menos con otro instrumento, volver a dividir la mitad inferior.

Aunque es evidente que el fraccionamiento de todos estas monedas se produjo en la propia época emiral, puesto que así aparecen contextualizadas, el contexto arqueológico de este cuarto de dírham ha permitido precisar algo más el momento en que fue partido. Este fragmento conserva parte de la fecha de acuñación por lo que ha podido ser datado en el año 197 h./812-3 J. C., en tiempos de al-Hakam I ${ }^{37}$.

\footnotetext{
37 En la moneda figuran las unidades (7) y las decenas (9), en este caso fácilmente distinguibles, faltando las centenas. Como por los rasgos epigráficos podemos ver claramente que no se trata de una moneda oriental, sólo caben dos opciones: que sea del año 197 h./812-3 d.C. y por tanto una moneda emitida bajo el mandato de al-Hakam I, o que sea del año 297 h./909-10 d. C., es decir, una de las últimas emisiones del emir 'Abd Allāh, quien tres años más tarde sería sucedido por el luego califa 'Abd al-Raḥmān III. Hemos descartado esta última opción y nos inclinamos por la datación más antigua, ya que epigráficamente los rasgos corresponden a las monedas de al-Hakam I, cuyas leyendas van deformando las letras hasta llegar a ser prácticamente ilegibles desde el año 198 h./813-4 J.C. hasta el final de su mandato. Esta deformación epigráfica es más acentuada y se da sobre todo en la segunda área, tal y como ocurre en el caso que estudiamos. Las monedas acuñadas por el emir 'Abd Allāh suelen tener un diámetro mayor (alrededor de $30 \mathrm{~mm}$ ), toda vez que no se conocen monedas de estos últimos años del gobierno de 'Abd Allāh, años marcados por fuertes revueltas internas que sin duda influyeron en las escasas emisiones que pudo hacer este emir y en la práctica ausencia de moneda al final de su mandato. Por el contrario, las monedas de al-Hakam I son muy abundantes y las acuñadas en el año 197 h./ 812-3 d. C. se conservan en gran cantidad. A estos argumentos puramente numismáticos hay que añadir el de carácter estratigráfico.
}

Al-Qanțara (AQ) XXVII 2, julio-diciembre 2006, pp. 337-374 ISSN 0211-3589 
Fue exhumado al suroeste del ábside de la basílica, dentro del grupo de unidades 35 (fig. 4b), que es el único espacio del barrio islámico que ha permitido documentar un contexto material anterior al abandono general del yacimiento. En este espacio y tras un primer abandono que sella un interesante contexto de uso ${ }^{38}$, se constata una colmatación cubierta por el estrato de regularización constructiva (UE 60.131) correspondiente a un cerramiento curvilíneo, que replantea el espacio urbano en su última fase. En ese estrato de regularización, situado entre dos fases constructivas islámicas, apareció el fragmento de dírham estudiado, cuya fecha de acuñación otorga un fiable límite post quem a esta remodelación del barrio islámico que, no conviene olvidarlo, no continuó habitado después de la novena centuria.

Por tanto, la fragmentación de este dírham debió de producirse en algún momento entre su fecha de emisión, 197/812-3, y la construcción de las últimas estructuras islámicas en el siglo IX, posiblemente no más allá de mediados de la centuria, si tenemos en cuenta que el momento de abandono del yacimiento ha sido datado por los materiales cerámicos en un momento avanzado de la segunda mitad del siglo noveno ${ }^{39}$. En consecuencia, cabe suponer que debió de transcurrir poco tiempo entre la emisión de la moneda y su fragmentación para ser utilizada como moneda menor. Si tenemos en cuenta que los dos bordes cortados de la pieza han sido realizados con diferente instrumental y por tanto presentan una fractura distinta, hay que concluir que, en el supuesto de que no ser coetáneos, la primera fragmentación de la moneda debió de hacerse en un momento muy próximo a su fecha de acuñación.

La temprana fragmentación de los dírhams emirales se muestra de manera más concluyente en el caso del dírham más moderno que por el momento hemos exhumado en el yacimiento: un fragmento correspondiente, como el anterior, a la cuarta parte de un dírham de características similares al que acabamos de describir (n. $\left.{ }^{\circ} 15\right)$. En este caso conserva la parte de la fecha correspondiente a las decenas y las centenas, careciendo de las unidades. Así, podemos afirmar que el dírham que nos ocupa fue acuñado en algún año de la década de los 30

\footnotetext{
38 Los materiales de este contexto de uso han sido publicados en un trabajo previo (Gutiérrez Lloret, S., Gamo Parras, B. y Amorós Ruiz, V., "Los contextos cerámicos", $150)$.

Ibidem, 156.

Al-Qanțara (AQ) XXVII 2, julio-diciembre 2006, pp. 337-374 ISSN 0211-3589
} 
del siglo III de la hégira, década en la que se produjo el cambio de gobierno de 'Abd al-Raḥmān II a Muḥammad I y que corresponde con el ámbito cronológico cristiano de los años 844 a 853 d. C. Esta pieza fue hallada en el interior de una casa islámica de una sola habitación, pero vinculada a un conjunto doméstico más extenso, formado por varias estructuras agrupadas en torno a un patio, que fueron construidas junto al muro norte de la ya amortizada basílica visigoda (fig. 4c).

El estrato en el que fue exhumado el dírham corresponde al momento de uso de la vivienda emiral, donde fueron hallados diversos elementos del ajuar doméstico, tales como una tinaja, una olla, un jarro y un candil de piquera corta vidriado en melado (fig. 6) ${ }^{40}$. Este repertorio se adscribe claramente a una cronología emiral, centrada en la segunda mitad del siglo IX, como confirma la difusión del vidriado monocromo y la propia moneda, a la vez que evidencia claramente la pronta fragmentación de la pieza en relación al momento de su acuñación. Ello indicaría que la necesidad de moneda fraccionaria era tal, que no había inconveniente alguno en partir un dírham recién salido de la ceca, si bien esas primeras manipulaciones procurarían producir fragmentos regulares de moneda. Está por estudiar si existe una evolución en la morfología de los fragmentos que tenga que ver con el tiempo que dicho fragmento lleva en circulación, es decir, si de un dírham se hacen en principio fragmentos regulares y reconocibles, como parece lógico, y cuando estos fragmentos llevan un tiempo en circulación se dividen en trozos aún más pequeños, o si por el contrario desde un primer momento un dírham era cortado en fracciones informes de diferentes tamaños y pesos ${ }^{41}$.

Una última observación que hemos podido constatar en los fragmentos de dírhams estudiados, es la que se refiere a la orientación del corte de las piezas. En todos los fragmentos de un cuarto de pieza, la moneda fue cortada en paralelo a las líneas de escritura de la primera área donde figura la profesión de fe, salvo en el ejemplo $n .^{\circ} 15$, en que

40 Ibidem, 150.

41 En relación a la morfología y corte de los fragmentos Canto García, A. y Marsal Moyano, E., "Hallazgo de moneda", afirmaban en relación a los más de cuatrocientos fragmentos del hallazgo de Iznájar que "no es posible atestiguar una regularidad en el corte o forma de los mismos, aunque en los ejemplares más pesados o cuya superficie es más amplia sí existe cierta tendencia a adoptar de tres cuartos, medios y cuartos de moneda (al margen de su peso real); según disminuye el peso de los mismos, la forma es cada vez más irregular".

Al-Qanțara (AQ) XXVII 2, julio-diciembre 2006, pp. 337-374 ISSN 0211-3589 
FiguRA 6.-Planta y materiales del contexto arqueológico de la moneda $n .^{\circ} 15$
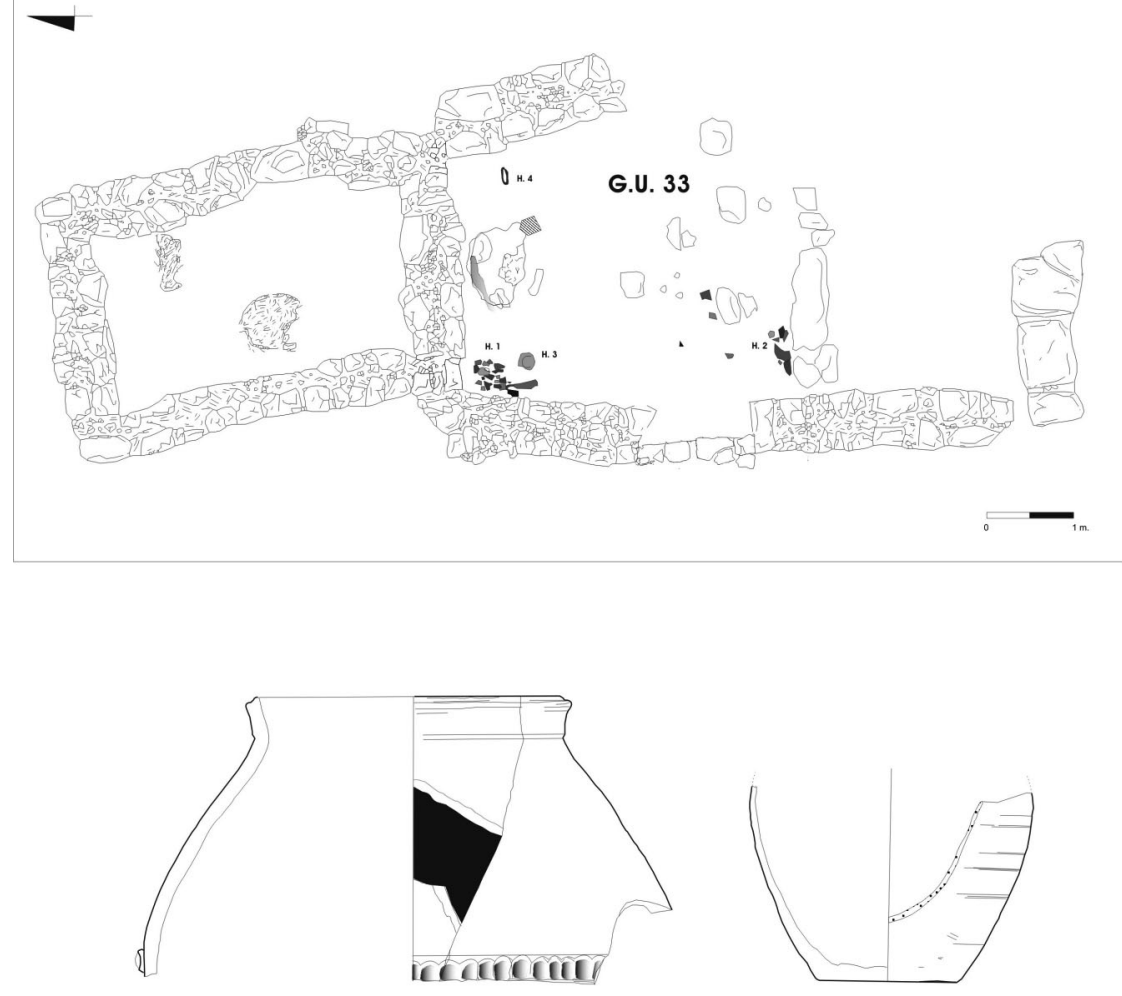

H.3

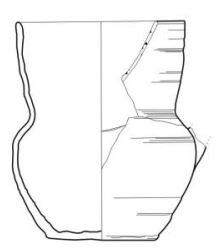

H.2

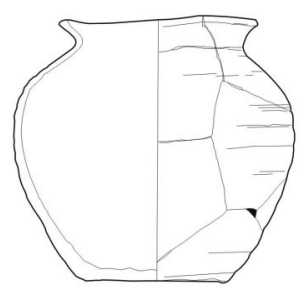

H.1

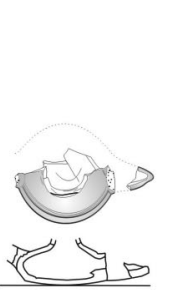

(3)

Al-Qanțara (AQ) XXVII 2, julio-diciembre 2006, pp. 337-374 ISSN 0211-3589 
esta fragmentación se hizo sobre las líneas de la sura 112 del Corán de la segunda área. Esta curiosa coincidencia que se da en los fragmentos del Tolmo y ocasionalmente en algunos dírhams partidos de otros hallazgos, nos lleva a preguntarnos si en el siglo IX, cuando estas monedas fueron divididas, las leyendas podían ser leídas y comprendidas - o al menos reconocidas - por la misma población que las convertía en moneda fraccionaria. Es difícil plantear este tipo de cuestiones, que afectan al grado de arabización y alfabetización de la población en general, a partir de un registro material tan específico como es el numismático, pero la recurrente concomitancia señalada parece sugerir que el texto de la profesión de fe era al menos reconocido visualmente sobre las monedas. En este sentido, la aparición en el mismo yacimiento de dos escritos espontáneos - una basmala y una marca de autoría - sobre cerámica emiral de producción local, permiten suponer, además de un significativo y temprano grado de alfabetización, que los habitantes del Tolmo estaban ya arabizados lingüísticamente en el siglo IX, con independencia de su origen indígena o foráneo ${ }^{42}$.

El único dírham sin fragmentar documentado hasta el momento es también el único que no fue acuñado en al-Andalus. Se trata de un dírham 'abbāsí (n. ${ }^{\circ} 11$ ) acuñado en tiempos del califa Hārūn al-Rašīd, concretamente entre los años 795-802 d. C. ${ }^{43}$, que fue exhumado en un estrato superficial del yacimiento formado por los derrumbes de las estructuras domésticas emirales. No es el único lugar de al-Andalus donde se ha localizado moneda 'abbāsí ${ }^{44}$, y aunque su presencia

42 Gutiérrez Lloret, S., "Cerámica y escritura".

43 Aunque la parte en que figura la ceca queda fuera del cospel, se ha podido llegar a establecer la cronología aproximada de esta pieza gracias a la leyenda de la segunda área, donde figura sobre las cuatro líneas de leyenda la letra "و" y bajo ellas el nombre "جعف" Según Lavoix, H., Catalogue des Monnaies Musulmanes, I, París, 1891, esta combinación solamente está presente en las emisiones de este califa entre los años 179 y 186 h./795 y 802 J.C., con lo que la pieza quedaría encuadrada en dicha horquilla temporal.

44 Se conocen algunos dírhames 'abbāsíes en conjuntos monetarios emirales: dos en el de Puebla de Cazalla (Ibrahim, T. y Canto García, A., "Hallazgo emiral") que son de 153 h./770 d. C. y de 180 h./796 d. C., respectivamente; otro de mediados del siglo IX en el hallazgo de Priego de Córdoba (Carmona Ávila, R. e Hinojosa Pareja, A. R., "Un conjunto monetario andalusí de plata procedente de la Junta de los Ríos (Priego de Córdoba)", Antiquitas, 10 (1999), 125-136) y otro más de la misma cronología en el conjunto localizado en Iznalloz, conocido como de Domingo Pérez (Vega Martín, M. y Peña Martín, S., "Del hallazgo de dírhames en Domingo Pérez (Iznalloz, Granada)", Al-Qantara, XXIII, 1 (2002), 155-192). En estos dos últimos casos la fecha de acuñación es medio siglo posterior a la del ejemplar del Tolmo.

Al-Qanțara (AQ) XXVII 2, julio-diciembre 2006, pp. 337-374 ISSN 0211-3589 
es anecdótica comparada con los hallazgos de numerario acuñado por otras dinastías también rivales, situadas en áreas geográficas más próximas, hay autores que consideran esta presencia de moneda 'abbāsí en al-Andalus un signo de la orientalización de la España musulmana ${ }^{45}$.

\section{El otro circulante: monedas antiguas y foráneas}

Los trabajos sistemáticos del Tolmo de Minateda han permitido igualmente constatar la pervivencia de numerario antiguo en el circulante de los primeros siglos de existencia de al-Andalus. De hecho, el grueso del monetario procedente de las excavaciones de la ciudad está formado por cobres tardorromanos, fundamentalmente de los siglos III y IV d. C. Hay que hacer notar, como ya se dijo, que son precisamente esas centurias las peor representadas en el yacimiento, que ha proporcionado escasísimos restos cerámicos y ninguno constructivo adscribibles, por el momento, a ese período.

Sin embargo, si por un momento aislásemos el estudio numismático del resto de los materiales del yacimiento - es decir, si lo descontextualizáramos-, se podría fácilmente afirmar que el asentamiento de donde proceden las monedas debía de haber sido un enclave importante durante los siglos III y IV d. C., a tenor del volumen del numerario de esa cronología. Nada más lejos de la evidencia arqueológica, que revela un impasse involutivo y demográfico entre los siglos II y VI d. C., sólo superado con la erección de un importante núcleo urbano visigodo. Nuestro ejemplo demuestra el riesgo que supone el estudio de los materiales numismáticos separadamente de su contexto estratigráfico, y que en ocasiones puede conducir a resultados no sólo confusos sino también erróneos ${ }^{46}$.

45 Vega Martín, M. y Peña Martín, S., "Del hallazgo de dírhames", 171.

46 Esta cuestión fue tratada ampliamente por J. M. Abascal a partir de los hallazgos de moneda romana, aportando numerosos ejemplos de época antigua y citando otros modernos e incluso contemporáneos. Concluye este autor que "aun admitiendo una serie de pautas generales en la circulación monetaria, parece imprescindible datar los hallazgos monetarios a partir de los contextos arqueológicos, a fin de establecer así los ritmos reales de circulación más allá de las fechas de emisión de cada serie" (Abascal Palazón, J. M., "Hallazgos arqueológicos y circulación monetaria. Disfunciones metodológicas en el estudio de la Hispania romana", Actas del IX Congreso Nacional de Numismática, Elche, 1994, 143-158, 154).

Al-Qanțara (AQ) XXVII 2, julio-diciembre 2006, pp. 337-374 ISSN 0211-3589 
La pervivencia de determinadas especies monetarias y especialmente el caso de los cobres tardorromanos es un hecho conocido desde antiguo ${ }^{47}$. Sin embargo, están por definirse las dimensiones y alcance de dicho fenómeno. En el Tolmo de Minateda se han podido documentar varios ejemplares de este numerario tardorromano y también más antiguo, aparecidos en contextos no sólo visigodos, donde la circulación de los viejos cobres bajoimperiales es habitual ${ }^{48}$, sino también en los niveles islámicos de la ciudad. Es más, ha sido precisamente la excavación de dichos niveles la que ha proporcionado el aporte más numeroso de materiales numismáticos. Los ejemplos de monedas romanas documentadas en los estratos de uso, abandono y destrucción de las viviendas emirales son muy abundantes y superan con creces el número de piezas islámicas exhumadas (Gráfico 3).

Los cobres del s. IV d. C. conforman la mayor parte del circulante. Sirvan como ejemplos una fracción de follis de Constantino de ceca indeterminada, datada en los años 307-319 d. C., y presente en el estrato de colmatación de la misma casa islámica ${ }^{49}$ en cuyo muro suroccidental apareció un felús del s. VIII (n. $\left.{ }^{\circ} 2\right)$; en el momento de colmatación de la vivienda la moneda de Constantino llevaba al menos cuatro siglos en circulación. A un contexto similar corresponden un nummus de Constancio II datado entre 355 y 361 d. C., otro de Julia-

47 Este fenómeno ya fue puesto de manifiesto por Navascués y de Palacio, J., "Tesorillo de cobre hispano-musulmán de Córdoba”, Numario Hispánico, VII (1958), 49-55. Años más tarde Crusafont i Sabater, M., “Un numerario visigodo de cobre?”, Gaceta Numismática, 74-75 (1984), 131-141, y El sistema monetario visigodo: cobre y oro, Barcelona-Madrid, 1994, 51, ponía en entredicho esta pervivencia y apuntaba la posibilidad de que se tratara de piezas romanas descubiertas en épocas posteriores y vueltas a poner en circulación. Actualmente, la gran cantidad de moneda antigua exhumada en contextos muy posteriores a su fecha de acuñación es difícilmente explicable por hallazgos casuales. El caso del Tolmo es un buen ejemplo.

${ }^{48}$ En el Tolmo de Minateda se ha constatado en varias ocasiones la presencia de cobres romanos en contextos de uso visigodos y junto a ajuares cerámicos datados en el siglo VII. Algunos ejemplos ya han sido dados a conocer: un antoniniano de Claudio II de 268-9 d. C. que fue hallado sobre el pavimento de un patio de una casa visigoda o un fragmento de un radiado de ceca oriental datado entre 295 y 307 d. C., exhumado en un estrato situado entre la última fase de la puerta visigoda de la ciudad y el pavimento correspondiente a la reforma del acceso en época islámica (Doménech Belda, C., "Los estudios de circulación", 54, y Dinares, dírhames, 92). A estos ejemplos se pueden añadir otros que serán tratados en un estudio de la fase visigoda de la ciudad en curso de elaboración.

${ }^{49}$ Se trata del G.U. 8 y concretamente el cobre de Constantino apareció en la U.E. 60.112 .

Al-Qanțara (AQ) XXVII 2, julio-diciembre 2006, pp. 337-374 ISSN 0211-3589 
GRÁFICO 3.-Circulante del barrio emiral
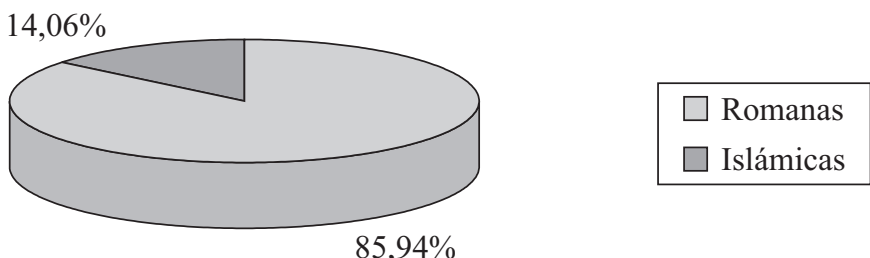

no acuñado entre el 355 y el 363 d. C. y un AE2 de Graciano que cronológicamente se sitúa entre el 378 y el 383 d. C. ${ }^{50}$ y que, a pesar de que esta especie monetaria se desmonetiza teóricamente en el año 395 d. C., la encontramos en un nivel arqueológico del s. IX. A estos ejemplares se pueden añadir otros más, exhumados tanto en contextos domésticos como viales.

Aunque en menor cantidad, también son abundantes las monedas acuñadas en el s. III d. C., siendo más rara, pero no inexistente, la presencia de moneda del Alto Imperio en estos estratos emirales. Es el caso de un as de Augusto acuñado en Cartago Nova entre 27 a. C. y 14 d. C.; $\mathrm{u}$ otro as con cabeza de Neptuno y tridente en anverso, y en el reverso, Victoria sobre proa y delante una leyenda vertical externa en griego; la cronología de este último es discutida pero parece que sería anterior a Augusto ${ }^{51}$. El ejemplar del Tolmo presenta un dentado en los bordes del cospel que debió de ser realizado en algún momento con posterioridad a su acuñación. Su exhumación en un estrato de colmatación de una de las estructuras domésticas islámicas ${ }^{52} \mathrm{y}$ junto a una fracción de follis de Constantino de inicios del s. IV d. C., sitúa a esta pieza en un momento muy alejado de su fecha de emisión. $\mathrm{Y}$ aún se detecta en estos niveles emirales la presencia de algunos po-

${ }^{50}$ Fueron hallados en las UU.EE. 61.576, 61.569 y 61.556 respectivamente.

51 Se trata de una moneda hispánica rara que ha sido estudiada por varios autores que coinciden en asignar esta emisión a la zona de la antigua Edetania. Recientemente Ripollés Alegre, P. P. y Llorens Forcada, M. M., Arse-Saguntum: historia monetaria de la ciudad y su territorio, Sagunto, 2002, 297, han propuesto una fecha posterior a 29-27 a.C. si el diseño del reverso está copiado de un denario de Octaviano con proa y Victoria, pero está por explicarse por qué tiene una leyenda griega.

52 U.E. 60.114 en el G.U. 9; se trata del nivel de colmatación equivalente al 60.112 en la habitación contigua, donde apareció el bronce de Constantino de principios del siglo IV.

Al-Qanțara (AQ) XXVII 2, julio-diciembre 2006, pp. 337-374 ISSN 0211-3589 
cos ejemplares más antiguos, como un divisor republicano del s. II a. C. ${ }^{53}$. Este fenómeno ha podido ser constatado en otros lugares como La Rábita de Guardamar, donde en niveles arqueológicos perfectamente datados en el s. IX fueron exhumados un denario de Vespasiano acuñado en Roma entre el 69 y el 73 d. C. y una moneda con monograma que podría fecharse entre los siglos V y VI d. C. ${ }^{54}$ También en las excavaciones de la ciudad de Cartagena ha aparecido un as ibérico en estratos bizantinos ${ }^{55}$.

Estas piezas tan antiguas pueden ser un circulante residual en los contextos islámicos, pero el numerario del bajo imperio difícilmente puede explicarse, a la luz de la abundancia y contextualización de los hallazgos, como un fenómeno de residualidad. Es un numerario que parece formar parte del circulante de la ciudad emiral del Tolmo, a la par con las monedas islámicas, si bien éstas están cada vez más presentes en las últimas fases del yacimiento. El análisis contextualizado de los hallazgos numismáticos sugiere que durante el siglo VIII la presencia de circulante romano sería abundante, toda vez que el islámico es escaso y de cobre. En la centuria siguiente el numerario antiguo sigue estando en circulación, pero el islámico va adquiriendo mayor representatividad, a la vez que la moneda de plata hace acto de presencia en la ciudad, si bien fragmentada para obtener valores monetarios menores. Este proceso de implantación y uso de la moneda propiamente islámica y de evanescencia del numerario antiguo tendría su culminación en el Califato, con la desaparición de los cobres, también los islámicos, de la circulación.

En este contexto de uso y circulación normal de moneda antigua, no es de extrañar la aparición de un pequeño bronce bizantino con valor de cuatro nummi junto a un fragmento de dírham del siglo IX (n. $\left.{ }^{\circ} 18\right)$. Este múltiplo de nummus corresponde a la serie conocida como cruz/delta que, dada su aparición en las excavaciones de Cartago Spartaria, ha sido identificada como una emisión local de dicha procedencia. M. Lechuga da una cronología a estas piezas basándose en sus contextos arqueológicos de finales del siglo VI e inicios del si-

53 Esta moneda corresponde a la U.E. 61.682, primer abandono de las casas islámicas GU 36, 37 y 38 están ya construidas. Por encima se construye el muro islámico 61.567.

${ }^{54}$ La catalogación de estas piezas se la debemos a J. M. Abascal; véase Doménech Belda, C., Dinares, dirhames, 92.

${ }^{55}$ Lechuga Galindo, M., "Una aproximación a la circulación”, 336.

Al-Qanțara (AQ) XXVII 2, julio-diciembre 2006, pp. 337-374 ISSN 0211-3589 
glo VII, ya que la mayor parte de ellas cuenta con contextos estratigráficos fiables ${ }^{56}$. Esta moneda de pequeño módulo $(10,2 \mathrm{~mm}$.) y grosor considerable $(1,9 \mathrm{~mm}$.) perfectamente puede haber circulado con el valor de un felús islámico.

Como se ha visto, los ejemplos podrían ser muchos y variados ya que, en rigor, todo el numerario romano bajoimperial exhumado en el yacimiento, lo ha sido en contextos visigodos e islámicos. Este circulante debió de llegar al Tolmo varias centurias después de haber sido acuñado o, por lo menos, eso cabe pensar mientras sigan sin encontrarse en el asentamiento los niveles de la fase bajoimperial que por el momento se muestran inexistentes. Otra cuestión será poder llegar a determinar cuándo y de dónde llegan estas monedas.

Sin duda, parte de estos cobres antiguos circula en época visigoda cuando se detecta una significativa utilización de numerario romano bajoimperial, que se continúa en el período emiral tal vez acentuada con la aportación de numerario proveniente del norte de África ${ }^{57}$. Este fenómeno se habría producido ya con la llegada de los bizantinos a la Península Ibérica, que provocó un aporte de numerario norteafricano, básicamente de monedas bizantinas, vándalas y tal vez también romanas que permanecían en circulación por el norte de África, como demuestran los trabajos de T. Marot y M. Llorens llevados a cabo en el yacimiento de La Punta de L'Illa de Cullera donde constatan también la pervivencia en la circulación de AE2 y AE3 a pesar de que teóricamente habían sido desmonetizados en el año 395 d.C ${ }^{58}$. La lle-

\footnotetext{
56 Rellenos constructivos de la fase fundacional del barrio bizantino, relleno de pozos asociados a las viviendas bizantinas o niveles de colmatación de esa fase (ibidem, 339).

57 Los datos obtenidos a partir de la contextualización de los registros numismáticos en El Tolmo de Minateda indican que el 39 por 100 de la moneda romana aparece en los niveles de viviendas domésticas del siglo IX. Este porcentaje desciende en los estratos del siglo VIII hasta un 30 por 100 y se reduce considerablemente en los niveles visigodos donde no llega al 15 por 100. Sin embargo, es posible que estos datos estén distorsionados debido al diferente carácter y extensión de los espacios excavados: ámbitos domésticos en el caso islámico mientras que la fase visigoda corresponde a un complejo monumental de carácter religioso y administrativo.

58 Esta cuestión ha sido tratada ampliamente por Marot i Salas, T., en especial en "Monedas vandals i bizantines a Pollentia", Gaceta Numismática, 99 (1990), 29-33; "Monedas vándalas y bizantinas procedentes de Santa Pola (Alicante)", Numisma, 237 (1996), 249-258, y “Aproximación a la circulación monetaria en la Península Ibérica y las Islas Baleares durante los siglos V y VI: la incidencia de las emisiones vándalas y bizantinas”, Revue Numismatique, 152 (1997), 157-190.
} 
gada de los musulmanes bien podría haber provocado de nuevo el mismo fenómeno: un aporte de numerario llegado desde el norte de África que se sumaría a las viejas monedas romanas que circulaban entre la población visigoda, para la mayor parte de la cual el oro acuñado por el Estado debía ser inalcanzable.

Además de las antiguas monedas, hay que añadir al circulante el numerario llegado de fuera de al-Andalus. Es el caso del dírham 'abbāsí al que ya nos hemos referido y de un dinero carolingio que ha sido fragmentado, igual que la plata andalusí, en este caso en una mitad. Se trata como decimos de un fragmento de media moneda con cruz en anverso y monograma de Karolvs en reverso, acuñada a nombre de Carlomagno en la Marca Hispánica ${ }^{59}$. Fue exhumado en la zona septentrional de la calle (fig. 3c) en un estrato de abandono y destrucción cuya superficie corresponde a un uso islámico previo a la construcción del barrio emiral. La moneda carolingia está presente en territorio andalusí en algunos conjuntos monetales ${ }^{60} \mathrm{y}$ en forma de hallazgos aislados particularmente en el área catalana, aunque no es muy abundante ${ }^{61}$. Pero lo cierto es que los dineros carolingios parecen integrarse sin problemas entre el circulante emiral, y son sometidos al mismo proceso de fragmentación que sufren los dírhams emirales a los que, tras la reforma de Carlomagno, se asemejan en diámetro y grosor.

\section{Conclusiones}

Es sabido que las monedas son en sí mismas restos materiales que se hallan a menudo en el curso de excavaciones arqueológicas y que son susceptibles de ser analizadas con procedimientos arqueológicos. Como documentos arqueológicos contienen información interna, en

59 Posiblemente fue acuñada en Ampurias o en Gerona y se trataría del tipo 1/2 de Crusafont i Sabater, M., Numismática de la Corona Catalana-Aragonesa Medieval (785-1516), Barcelona, 1982.

${ }^{60}$ Como, por ejemplo, el cordobés conocido por Sagrada Familia (Santos Jener, S. de los, "Monedas carolingias en un tesorillo de dirhemes del Emirato cordobés", Numario Hispánico, 5 (1957), 79-87), o el de Puebla de Cazalla (Ibrahim, T. y Canto García, A., "Hallazgo emiral").

${ }^{61}$ Sobre la moneda carolingia y su dispersión por la Península Ibérica, véase Balaguer, A. M. y Canto García, A., "Al-Andalus y los carolingios, un singular testimonio monetario", Gaceta Numismática, 85 (1987), 41-52.

Al-Qanțara (AQ) XXVII 2, julio-diciembre 2006, pp. 337-374 ISSN 0211-3589 
tanto que objetos per se, y aportan información externa en cuanto que forman parte de un contexto estratigráfico. Esa información arqueológica externa tiene mucho que ver con su condición de testimonio fechado, que proporciona a la arqueología un elemento de datación relativa de inestimable valor. No obstante, este valor cronológico no es obvio ni evidente, ya que la fecha que contiene una moneda constituye necesariamente un terminus post quem, que no data su momento de uso sino el de su acuñación, mientras que la larga perduración de ciertos tipos monetales puede introducir significativos desfases cronológicos. La contextualización estratigráfica de los repertorios monetarios se manifiesta, por tanto, como el mejor sistema de datación de los mismos y, a la vez, de los estratos que los contienen ${ }^{62}$.

En este sentido, el análisis abordado en los contextos altomedievales del Tolmo ha sido particularmente revelador: en época islámica el registro nos muestra una ciudad donde la moneda circula profusamente; sin embargo, en el panorama de alta monetización que evidencian los niveles islámicos excavados en el yacimiento, los ejemplares islámicos suponen tan sólo el 14 por 100 del numerario, frente al 86 por 100 de moneda romana circulante en época emiral. La inmensa mayoría del numerario estudiado procede de contextos arqueológicos de uso, cuyo significado es, como señalara P. Delogu ${ }^{63}$, completamente diferente del de los depósitos intencionales. El hallazgo de material numismático antiguo en ambas situaciones tiene implicaciones muy diferentes: mientras que en el primer caso se trata de residualidad circulante (tipos monetales antiguos que se mantienen en uso en sistemas monetarios más modernos), en el segundo se trata de residualidad atesorada (monedas antiguas fuera de circulación conservadas por su valor metálico).

Las monedas romanas estudiadas en los contextos emirales del Tolmo proceden de estratos formados en el yacimiento durante su ocupación cotidiana (nivelaciones constructivas, estructuras arquitectónicas, depósitos sobre los pavimentos, desechos, etc.) o su abandono y destrucción. Son normalmente de escaso valor intrínseco y es de suponer que eran de uso corriente y circulaban en el momento de su extravío. Desde ese punto de vista, puede afirmarse que el material

${ }^{62}$ Sobre este particular, cf. Gutiérrez Lloret, S., Arqueología. Introducción a la historia material de las sociedades del pasado, Alicante, 1997, 135 y ss.

${ }^{63}$ Introduzione allo studio della Storia Medievale, Bolonia, 1994, 212. 
numismático romano constituye parte del circulante de la ciudad visigoda y posteriormente emiral. En consecuencia resulta lícito plantear si este numerario romano no es ni siquiera residual, puesto que la mayoría de estas piezas son monedas bajoimperiales de los siglos III y IV, que fueron acuñadas en unos períodos en los que resulta improbable, por el momento, que el asentamiento estuviese habitado.

De hecho, el circulante del siglo VIII está formado mayoritariamente por numerario antiguo, viejos cobres romanos, a los que se suma algún felús de acuñación islámica. A este predominio de los cobres habría que añadir, en la centuria siguiente, algunos dírhams fragmentados para ser utilizados como moneda fraccionaria. A la luz de estos datos, la pretendida inexistencia de moneda en yacimientos islámicos parece cada vez más cuestionable, por lo menos en el lo que respecta al Tolmo de Minateda.

La contextualización de los hallazgos ha permitido un fluido diálogo entre los registros cerámicos y numismáticos, proporcionando un límite post quem fiable a los primeros y contribuyendo a fechar el fraccionamiento o circulación de los segundos. Los mejores ejemplos son la datación del barrio emiral del Tolmo y la de los contextos postvisigodos del palacio. En este último caso, la aparición de un felús en uno de sus niveles de uso ha permitido reconocer la utilización del conjunto palatino en época emiral y relacionar esa eventual utilización con la aparición de ambientes domésticos constatada en la basílica aneja. El siglo VIII era invisible desde una perspectiva ceramológica; la estratigrafía lo ha materializado con ayuda de la numismática, al tiempo que ha hecho patente la hasta ahora prácticamente invisible circulación monetaria del siglo VIII, conformada en su mayoría por numerario tardorromano.

Este panorama se ha podido obtener a partir del estudio de las piezas como parte de un registro más amplio, inmerso en la secuencia estratigráfica general del yacimiento. Desde esta perspectiva, la contextualización arqueológica de los hallazgos monetarios se ha revelado como una potente herramienta metodológica, capaz de iluminar aspectos históricos y económicos que escaparían a un análisis numismático puramente taxonómico y ajeno a la secuencia que determina el orden temporal de su deposición. 


\section{Catálogo de monedas islámicas}

1. Felús. Emirato Dependiente. Siglo VIII.

Peso: 4,2 g. Módulo: 15,5 mm. Grosor: 3,4 mm. Posición de cuños: 8 .

Referencias: Frochoso ${ }^{64}$, IIc.

Número de inventario: 60.295/64.

2. Felús. Emirato Dependiente. Al-Andalus. Siglo VIII.

Peso: 5,8 g. Módulo: 17,1 mm. Grosor: 5,1 mm.

Referencias: Miles ${ }^{65}, 28$; Frochoso, XVII.

Número de inventario: 62.591.

3. Felús. Siglo VIII.

Peso: 6,2 g. Módulo: 19,2 mm. Grosor: 3,3 mm. Posición de cuños: 7.

Número de inventario: $62.475 / 9$

4. Felús. Emirato Dependiente. Siglo VIII.

Peso: 3,1 g. Módulo: 14,4 mm. Grosor: 3,4 mm. Posición de cuños: 12 .

Referencias: Frochoso, ¿XXf?

Número de inventario: 00/sup.

5. Felús. Emirato Dependiente. Siglo VIII.

Peso: 4,5 g. Módulo: 18,9. Grosor: 2,3 mm.

Número de inventario: 62.600/1608.

6. Felús. Emirato Dependiente. Al-Andalus. 108/726-7.

Peso: 4,6 g. Módulo: 20,8 mm. Grosor: 2,5 mm. Posición de cuños: 3

Referencias: Miles, 8 b/c/d; Frochoso, XIXb.

Número de inventario: 1.813/1504

7. Felús. Emirato Dependiente. S. VIII.

Peso: 5,8 g. Módulo: 17,5 mm. Grosor: $4 \mathrm{~mm}$.

Referencias: Miles, 26; Frochoso, IIa.

Número de inventario: 02/sup. 1

64 Frochoso Sánchez, R., Los feluses de al-Andalus.

65 Miles, G. C., The Coinage of the Umayyads of Spain, Nueva York, 1950. 
8. Felús. Emirato Dependiente. Siglo VIII.

Peso: 3,2 g. Módulo: 12,0 mm. Grosor: 3,6 mm.

Número de inventario: 61.002/273.

9. Felús. Emirato Independiente. Siglo IX.

Peso: 1,5 g. Módulo: 20,4 mm. Grosor: 0,4 mm.

Número de inventario: 1486/29.

10. Fragmento de felús. Emirato Independiente. ¿Atribuido a Muhammad I? ¿241/855-6?

Peso: 0,5 g. Módulo: - Grosor: 1,0 mm.

Número de inventario: 03/sup.

11. Dírham 'abbāsí. Hārūn al-Rašīd. 179-186/795-802.

Peso: 2,45 g. Módulo: 25,5 mm. Grosor: 0,5 mm. Posición de cuños: 3 .

Referencias: Lavoix ${ }^{66}, 793$.

Número de inventario: 62.600/1607.

12. Fragmento de dírham emiral.

Peso: 1,6 g. Módulo: 28,0 mm. Grosor: 0,5 mm.

Número de inventario: 60.474/2290.

13. Fragmento de dírham emiral. Al-Andalus. Siglo IX.

Peso: 0,3 g. Módulo: - Grosor: 0,4 mm. Posición de cuños: 8.

Número de inventario: 60.744/294B.

14. Fragmento de dírham emiral. Al-Andalus. Al-Hakam I. 197/812-813.

Peso: 0,7 g. Módulo: - Grosor: 0,5 mm. Posición de cuños: 11.

Referencias: Miles, 88 .

Número de inventario: 61.131/123.

15. Fragmento de dírham emiral. Al-Andalus. 'Abd al-Raḥmān II/Muhammad I. 23X/844-853.

Peso: 0,7 g. Módulo: - Grosor: 0,6 mm. Posición de cuños: 8. Número de inventario: 61.139/151.

${ }^{66}$ Lavoix, H., Catalogue des Monnaies.

Al-Qanțara (AQ) XXVII 2, julio-diciembre 2006, pp. 337-374 ISSN 0211-3589 
16. Fragmento de dírham emiral. Al-Andalus.

Peso: 0,8 g. Módulo: - Grosor: 1,0 mm.

Número de inventario: 1820/172.

17. Fragmento de dírham emiral.

Peso: 0,3 g. Módulo: - Grosor: 0,9 mm. Posición de cuños: 6.

Número de inventario: 62.605/24.

18. Fragmento de dírham emiral. Al-Andalus. 2XX h./s. IX d. C.

Peso: 0,5 g. Módulo: - Grosor: 0,7 mm. Posición de cuños: 11.

Número de inventario: 61.594/1140.

19. Fragmento de dírham emiral.

Peso: 0,2 g. Módulo: - Grosor: 0,4 mm.

Número de inventario: 61.882/39. 